\title{
Ambrosio Borsano: un exponente de la escuela de ingeniería militar de Milán al servicio de la Monarquía Hispánica (1633-1661)*
}

\author{
Paolo Bossi ${ }^{1}$ \\ Politecnico di Milano \\ paolo.bossi@polimi.it \\ Francesc Nadal Piqué \\ Universitat de Barcelona \\ fnadal@ub.edu
}

RESUMEN: En este artículo se examina una etapa crucial en la vida de Ambrosio Borsano, uno de los principales ingenieros militares de la Europa de la segunda mitad del siglo XVII: la de su formación como cartógrafo militar. Una etapa sobre la que se disponía de contadas y dispersas referencias. En el mismo se intenta resolver, en primer lugar, la cuestión de su nacimiento y el marco familiar milanés en el que se educó. Después, se describen las actividades militares que llevó a cabo, entre 1648 y 1658, en el norte de Italia, durante las cuáles conoció al que terminaría siendo su maestro:

* Este trabajo es el resultado de una investigación llevada a cabo a cuatro manos por los autores. La estructura general del texto y la selección de los temas se han creado y desarrollado de forma conjunta. El procesamiento posterior de los apartados relativos a «La ciudad de Milán y el joven Borsano (1633-1648)» y «Gaspare Beretta y la escuela de ingeniería militar de Milán» se debe a Paolo Bossi; mientras que el de los apartados «De soldado a ayudante de ingeniero militar: Borsano y la guerra franco-española en el norte de Italia» y «De un frente militar a otro» es obra de Francesc Nadal.

Archivos: AGMM: Madrid, Archivo General Militar; AGS: Simancas, Archivo General, ASDMi: Milán, Archivio storico della Diocesi di Milano; DSA: Duplicati e status animarum; PSMB: Archivio della parrocchia di Santa Maria Beltrade a Milano (hoy suprimida); VP: Sezione X. Visite pastorali e documenti aggiunti; ASMi: Milán, Archivio di Stato; ASPSMS: Milán, Archivio storico della parrocchia di Santa Maria Segreta; BCBPv: Pavía, Biblioteca civica «Carlo Bonetta»; BNE: Madrid, Biblioteca Nacional de España; BTMi: Milán, Archivio storico cívico e Biblioteca Trivulziana.

1 ORCID iD: http://orcid.org/0000-0002-1588-8298.

2 ORCID iD: http://orcid.org/0000-0001-9777-5336. 
Gaspare Beretta, ingeniero mayor del ejército español en el Estado de Milán. A continuación, se analiza la formación que recibió como cartógrafo militar de Beretta y que es preciso situarla en el marco de la escuela de ingeniería militar de Milán. El artículo se cierra explicando el último capítulo de su etapa de formación: el de su traslado a la península Ibérica en 1661 para luchar contra los independentistas portugueses.

PALABRAS CLAVE: Milán; cartografía militar; ingeniería militar en Milán; Ambrosio Borsano; Gaspare Beretta; Portugal.

Ambrosio Borsano: an exponent of the Milan Military Engineering School in the service of the Hispanic Monarchy (1633-1661)

ABSTRACT: Ambrosio Borsano was one of the main European military engineers in the second half of the seventeenth century This article examines a key period in his life for which references are limited and dispersed: his training as a military cartographer. We begin by trying to solve the issue regarding his birth and the family context in Milan where he was educated. Next, we consider his military activities in the north of Italy between 1648 and 1658. During these activities, he met Gaspare Beretta, chief engineer of the Spanish army in the State of Milan, who would finally become his teacher. We go on to to analyse the training he received as Beretta's military cartographer and place it in the framework of the Milan Military Engineering School. The article concludes with the final episode in his training when he moved to the Iberian Peninsula in 1661 to fight against the Portuguese independence movement.

KEY WORDS: Milan; military cartography; military engineering in Milan; Ambrosio Borsano; Gaspare Beretta; Portugal.

CÓMO CITAR ESTE ARTÍCULO/CITATION: Bossi, Paolo y Nadal Piqué, Francesc, «Ambrosio Borsano: un exponente de la escuela de ingeniería militar de Milán al servicio de la Monarquía Hispánica (1633-1661)», Hispania, 77/257 (Madrid, 2017): 673-704. doi: 103989/hispania.2017.018.

Ambrosio Borsano (Milán, 1633-Guissona, 1708) fue uno de los principales ingenieros militares europeos de la segunda mitad del siglo XVII. Durante más de cincuenta años sirvió a la Monarquía Hispánica, primero como soldado y después como ingeniero militar. Como ingeniero llevó a cabo importantes trabajos en el campo de la arquitectura militar tal como lo ponen de manifiesto sus destacadas intervenciones en las fortalezas de Cardona y CastellCiutat en la Seu d'Urgell'3. Pero, también realizó una importante labor en el

${ }^{3}$ ESPINO, 1999: 93-116. ALFARO, 2011: 103-110. 
ámbito de la cartografía militar, que entonces estaba experimentando una auténtica revolución ${ }^{4}$. Así, fue el autor de numerosos planos, plantas, perfiles y vistas de ciudades y plazas fuertes ibéricas, así como del mapa titulado $E l$ Principado de Cattaluña y Condados del Rossellón y Cerdaña, que firmó en 16875 .

A pesar de ello, una buena parte de su vida y de sus actividades profesionales presenta numerosas lagunas. Una situación que, afortunadamente, ha empezado a cambiar en los últimos años gracias a la publicación de diversos trabajos sobre algunas de sus actividades ${ }^{6}$. El presente trabajo pretende contribuir, en este sentido, a cubrir dos de estas lagunas: la relativa a su nacimiento y a su marco familiar y la relativa al período de su formación cartográfica en la escuela milanesa de ingeniería militar ${ }^{7}$.

Para conseguir este objetivo se han consultado, en primer lugar, diversas fuentes primarias conservadas en archivos italianos y españoles como el Archivio di Stato di Milano, el Archivio Storico della Diocesi di Milano, el Archivo General de Simancas o el Archivo General Militar de Madrid. También se ha utilizado la bibliografía existente relativa al contexto histórico y a la revolución que experimentó la cartografía militar durante los siglos XVI y XVII.

A fin de explicar los resultados de esta investigación se ha dividido el trabajo en cinco apartados diferentes. En el primero se abordan las relaciones del joven Borsano y su familia con la ciudad de Milán durante el segundo tercio del siglo XVII. En el segundo se describe el contexto bélico del periodo 1645-1661, durante el que Borsano luchó en el frente del norte de Italia, primero, como soldado y, después, como ayudante ingeniero militar a las órdenes de Beretta. En el tercero se trata el tema de Gaspare Beretta y la escuela de ingeniera militar de Milán, prestándose una especial atención a las relaciones de Beretta con Borsano y a las estrechas relaciones cartográficas entre los ingenieros militares del Ducado de Milán con los del Estado saboyano. En el cuarto aparatado se explica la llegada de Borsano a la península Ibérica en 1661, a donde fue destinado para combatir a los independentistas portugueses. El trabajo se cierra con un breve apartado de conclusiones.

${ }^{4}$ POLLAK, 1991. WARMOES, D’ORGEIX y VAN DEN HEUVEL, 2003. SÁNCHEZ, TESTÓN y SÁNCHEZ, 2004. BUISSERET, 2004: 133-171; 2007b: 1504-1521. MONSAINGEON, 2008, 233-261. BRANACH, 2015.

5 GALERA, 2001: 133-135. TESTÓN, SÁNCHEZ y SÁNCHEZ, 2003. BUISSERET, 2007a: 1069-1094. NADAL, 2008: xxiii-xxix. SÁNCHEZ, SÁNCHEZ y TESTÓN: 2014: 4447 y 77-89. NADAL, 22 (Barcelona, 2015): 19-32.

${ }^{6}$ MARTÍ y ESPINO, 2013, 9-15. LLOBET, 2014: 22, 67-68 y 122. NADAL, 22 (Barcelona, 2015): 19-32.

7 CÁMARA, 2005: 13-29. COBOS y CASTRO, 2005: 87-91. BUISSERET, 2007a: 1091. 


\section{La CIUdAd de Milán y EL JOVEn Borsano (1633-1648)}

E1 7 de febrero de 1632 el Tribunal de la Sanidad declaraba a Milán finalmente liberada de la terrible epidemia de peste que la había flagelado desde finales de octubre de 1629 como consecuencia dramática de la segunda guerra de Mantua. A partir de esa declaración, se reanudó de nuevo el libre comer$\mathrm{cio}^{8}$. En la ciudad, sobre una población de aproximadamente 130.000 habitantes se habían registrado durante aquellos meses, según estimaciones basadas en los documentos oficiales, alrededor de 50.000 muertos. Un número impresionante, que representaba aproximadamente el triple de los muertos por la peste de un año de duración que comenzó en julio de $1576^{9}$ y que aún estaba bien presente en la memoria de toda la población ${ }^{10}$.

Entre finales de septiembre y comienzos de octubre de 1630, las abundantes lluvias caídas después de un largo período de grave sequía habían reducido sensiblemente la agresividad de la epidemia, de manera que durante los primeros meses de 1631 se produjeron pocos contagios en la capital del $\mathrm{Du}-$ cado. A medida que el miedo iba cediendo, se fue restableciendo, de forma progresiva, la normalidad. Pasado más de un año, a finales de septiembre de 1630, los registros de la parroquia de Santa Maria Beltrade ${ }^{11}$ en Porta Ticinese empezaron a documentar nuevas bodas. En un mismo día, el 15 de octubre de 1630, Giovanni Ambrosio Borsano ${ }^{12}$ se casó con Clara Riva; el hermano de ésta, Carlo Riva, se esposó con Flavia Modroni; y Carlo Borsano contrajo matrimonio con Barbara Moderati, viuda de Giovanni Ambrosio Pozzo con quien había tenido, en mayo de 1625, su primera hija: Elena Maddalena ${ }^{13}$.

${ }^{8}$ LUPI, 1990: 57. El primer caso de peste en Milán se registró en la parroquia de San Babila el 22 de octubre de 1629.

${ }^{9}$ En aquella ocasión, los muertos habían sido aproximadamente 17.000.

${ }^{10}$ La construcción del templo cívico de San Sebastiano, cuya realización en honor del santo mártir, tradicionalmente considerado de origen milanés, había tenido lugar por voluntad del arzobispo Carlo Borromeo como ofrenda por el fin del contagio. Las obras empezaron en septiembre de 1577 y se terminaron hacia 1615 , consagrándose el templo en 1616.

${ }^{11}$ En aquella época, la antigua iglesia de Santa Maria Beltrade, cuya fundación data del año 836, se renovó radicalmente según una reforma proyectada por el arquitecto milanés Giuseppe Meda, que concluyó en 1597. Por efecto de esta obra, el templo, que fue transformado ulteriormente en 1717 y en 1794, restaurado totalmente en 1852 y destruido en 1926, había perdido definitivamente su planta circular original, de la que derivaba el nombre de Santa Maria Rotonda Beltrade y se presentaba con una nave única con dos capillas por lado. Véase FIORIO, 2006: 424.

12 Aquí y en todo el texto se ha preferido utilizar la forma arcaica del nombre «Ambrogio», es decir «Ambrosio», recurrente en los documentos de la época. Forma que coincide, por otro lado, con la denominación castellana de este nombre.

${ }^{13}$ Battesimi dal 1619 al 1647, ASDMi, PSMB. 
Giovanni Ambrosio, hijo de Tommaso, y Carlo, hijo de Ambrosio, eran indudablemente parientes cercanos. Lo desvela no sólo el apellido en común sino también el hecho de que, aunque residían en dos parroquias diferentes - Santa Maria Segreta el primero y Santa Maria Beltrade el segundo-, decidieron casarse en la misma iglesia el mismo día ${ }^{14}$.

\section{La familia Borsano: Francesco y Tommaso}

De Tommaso, padre de Giovanni Ambrosio y de un segundo hijo varón, Giovanni Pietro, sabemos que era hijo de Francesco, armero residente en la parroquia de Santa Maria Segreta durante la segunda mitad del siglo XVI'15. Sus productos se identificaban con el símbolo (marca) de una torre, como los de Giovanni Domenico Vigoredo otro célebre armero milanés ${ }^{16}$. Además, la vivienda de Francesco, que tenía anexado el taller de la familia y la correspondiente bodega (canepa), ocupaba, según un contrato de alquiler estipulado en 1562 con el Luogo Pio della Misericordia, parte de un edificio en Contrada degli Armaioli (contrata Armorariorum). Mientras que la parte restante estaba concedida precisamente a Giovanni Domenico y a sus dos hermanos, Giovanni Francesco y Agostino, que desarrollaban allí sus actividades ${ }^{17}$. Según los documentos consultados, el taller de los Vigoredo era bastante más grande que el de Borsano. De ahí la diferencia del precio del alquiler (más de 150 liras por año, contra poco menos de 100) y el mayor espacio disponible, ya que además de contar con otra bodega con bóveda se componía de un fundago y una fragua. Evidentemente, como solía ocurrir por entonces en aquel arte ${ }^{18}$, entre los Vigoredo y el Borsano se había establecido una estrecha colaboración. Así, Giovanni Domenico y sus hermanos eran titulares del taller y se ocupaban de la mayoría de la producción y de los encargos más difíciles, ya que contaban con su propia fragua, mientras Francesco actuaba como proveedor de confianza de piezas específicas o de series completas de componentes.

Santa Maria Segreta y Santa Maria Beltrade eran precisamente las parroquias de los armeros milaneses, constituyendo, de hecho, los límites, respec-

${ }^{14}$ Un ulterior indicio, por más marginal que sea, del parentesco directo entre Carlo y Giovanni Ambrosio Borsano radica en el hecho de que ambos acudían al notario milanés Giovanni Guizzetti, hijo de Giovanni Battista, activo entre 1635 y 1679.

${ }^{15}$ Francesco Borsano había nacido en 1536 según consta en el registro de población de la parroquia de Santa Maria Segreta de 1586, que a los cincuenta años lo registra como posesor de varias casas, incluida aquella en la que vivía; Status animarum S. Mariae Secretae MDLXXXVI, ASDMi, VP, Santa Maria Segreta, 1514-1602, I.

${ }^{16}$ GODOY y LEYDI, 2003: 521.

1720 de junio de 1618, ASMi, Notarile, 26317.

18 GODOY y LEYDI, 2003. 
tivamente septentrional y meridional, del barrio donde se concentraban sus trabajadores (coincidente con las actuales calles Via Armorari, Via Spadari y, más al sur, Via Speronari). Unos trabajadores conocidos en las cortes de toda Europa durante el siglo XVI y parte del XVII por los espléndidos logros de su arte $^{19}$. Sin embargo, a finales del siglo XVI, el sector comenzó a verse afectado por la aguerrida competencia de los armeros de Brescia y del Véneto, así como por la más o menos progresiva caída de la demanda de suministros militares, debida al desplazamiento de los escenarios bélicos hacia el norte de Europa. Como consecuencia de ello, los artesanos de los talleres más pequeños se vieron obligados a diversificar su actividad y dar prioridad, en algunos casos, a producciones originariamente marginales, a emigrar o a poner fin a su actividad ${ }^{20}$. En 1587, en un intento casi desesperado de contrarrestar la crisis de la producción local, los armeros milaneses se constituyeron en universidad. Tres años más tarde, en 1590, la misma corporación se hizo cargo de la transformación de una capilla en la iglesia de Santa Maria alla Rosa hoy destruida y que se encontraba situada en la céntrica parroquia de San Mattia alla Moneta. Esta transformación tenía como objetivo hacerla conforme alle altre desde el punto de vista de las dimensiones, pero di melior belezza delle altre $^{21}$, quedando reservada no sólo a la celebración de la misa, sino a la sepultura de sus difuntos.

Francesco Borsano fue uno de los testigos que asistieron, tras la muerte de Giovanni Domenico acaecida en 1564, a la redacción del inventario de los bienes del maestro ${ }^{22}$. Los dos hermanos Vigoredo siguieron compartiendo con él hasta su muerte, ocurrida entre abril de 1593 , fecha de su testamento ${ }^{23}$, y finales de julio de $1594^{24}$, el edificio en el que se encontraban sus talleres. A partir de entonces, la colaboración prosiguió con Tommaso Borsano, hijo nombrado por Francesco como único heredero. Más tarde, tras la muerte de Giovanni Francesco, acaecida después de 1598, la actividad familiar fue continuada por el tercer hermano Vigoredo, Agostino. Éste, una vez deducidas las cuotas de herencia de los sobrinos, resultaba, al menos hasta abril de 1609, aún cercano a Tommaso Borsano ${ }^{25}$. En los años siguientes tuvo lugar un

${ }^{19}$ GODOY y LEYDI, 2003: 26.

${ }^{20}$ GODOY y LEYDI, 2003: 26. RIZZO, 2011.

2120 de enero de 1590, ASMi, Notarile, 18210.

227 de julio de 1564, ASMi, Notarile, 12971. Citado en GODOY y LEYDI, 2003: 521.

${ }^{23}$ Se habla de esto en Recognitio libell.[oru]m fr.[atr]um de Borsano del 20 de junio de 1618; ASMi, Notarile, 26317. El testamento, registrado por el notario Giovanni Battista Alfieri («de Aliferis») el 2 de abril de 1593 no ha sido encontrado.

${ }^{24}$ El 30 de julio de 1594 Francesco resulta ser ya heredero de Tommaso, ASMi, Notarile, 20454.

${ }^{25}$ Ver la Recognitio libell.[oru]m fr.[atr]um de Borsano del 20 de junio de 1618, ASMi, Notarile, 26317. 
cambio generacional tan claro como natural: Camillo Giulio, Paolo Antonio, Stefano, Annibale y Filippo - que en 1601 se había ido seis años a España con otros armeros milaneses - ${ }^{26}$ sucedieron a Agostino y, desde diciembre de 1613, el Giovanni Ambrosio del que estamos hablando sucedió con su hermano menor Giovanni Pietro ${ }^{27}$ a Tommaso ${ }^{28}$.

\section{La familia Borsano: Giovanni Pietro}

Precisamente, en abril de $1616^{29}$, Giovanni Pietro, próximo a su partida en calidad de soldado de infantería (miles levis armaturae) hacia la caserma identificable quizás con el castillo hoy considerablemente reformado-, de San Bassano Cremonese (in loco Bassiani Cremonensis) y, ante la perspectiva de una larga ausencia, nombró a su hermano apoderado y, en caso de muerte, heredero universal.

Pocos meses antes, el 21 de junio de 1615, se había firmado el segundo tratado de Asti entre Carlo Emanuele I de Saboya y Juan de Mendoza y Velasco, marqués de Hinojosa y gobernador de Milán, que había puesto fin a la campaña de los españoles por la conquista de Monferrato. Hinojosa, que había causado un grave perjuicio diplomático al prestigio de la corona de España con una conducta demasiado agresiva hacia los Saboya, fue sustituido al poco tiempo, el 19 de enero de 1616. Su cargo fue ocupado por Don Pedro Álvarez de Toledo Osorio, marqués de Villafranca, a quien se le encargó aplastar por la fuerza la protervia de los italianos ${ }^{30}$. Estando el ejército ocupado en el Piamonte, el nuevo gobernador había creado inmediatamente una milicia no española para mantener el orden público tanto en Milán como en el ducado. Su creación no fue un proceso ni rápido, ni mucho menos indoloro ${ }^{31}$, sin embargo se acentuó durante las décadas siguientes, especialmente por la progresiva movilización de la infantería ibérica, pero con efectos tangibles desde el comienzo.

La incorporación de Giovani Pietro a la milicia milanesa pone de manifiesto como una parte de la familia Borsano participó, al igual que la de Gabrio

${ }^{26} 5$ de agosto de 1601, ASMi, Registri delle Cancellerie dello Stato, XXII, 44. GODOY Y LEYDI, 2003: 571.

${ }^{27}$ Los status animarum de la parroquia de Santa Maria Segreta atribuyen a Giovanni Pietro 19 años en 1610 (un año más que Giovanni Ambrosio) y 34 años en 1637; ver Stato dell'anime della Par[rocchi] a di S.ta Maria Seg[re]ta dell'anno 1631 y Stato delle Anime della cura di S.ta Maria Secreta del anno 1637, ASDMi, VP, Santa Maria Segreta, 1566-1637, 2.

${ }^{28}$ Tommaso Borsano fue sepultado en la iglesia de Santa Maria Segreta el 23 de diciembre de 1613, Morti dal $1^{\circ}$ gennaio 1586 al 26 dicembre 1639, ASPSMS.

299 de abril de 1616, ASMi, Notarile, 23835.

30 SPINI, 1965: 523.

${ }^{31}$ MAFFI, 2007: 118-119. MAFFI, 2009: 244-267. 
Serbelloni alrededor de un siglo antes y muchas otras del Ducado, en la estrategia imperial de la Monarquía Hispánica ${ }^{32}$. Además, el hecho de que su principal actividad fuera la de armero nos permite creer que mantuvo relaciones con el ejército español destacado en el Estado de Milán.

Alejado de la ciudad durante varios años (ausente, indudablemente, en junio de $1618^{33}$ y, casi seguramente, en octubre de $1619^{34}$ y de nuevo en $1631^{35}$ ), a finales de julio de 1635 , de urgencia en su propio domicilio y, luego, en la iglesia de Santa Maria Segreta, Giovanni Pietro bautizó a su hija Vittoria Felice, fruto de su matrimonio con Caterina y de constitución enfermiza desde los primeros días de su nacimiento ${ }^{36}$. Más tarde, en noviembre de 1636, se convirtió en tutor de Vittoria Camilla Borsano, de apenas un año, ya que el padre de ésta, su hermano Giovanni Ambrosio, había muerto poco tiempo antes en Vigevano como consecuencia, muy probablemente, de los combates que tuvieron lugar en esta ciudad en junio de aquel año cuando las tropas piamontesas, involucradas por la corte francesa en el proyecto de atacar a los españoles en todas partes y echarlos de Italia ${ }^{37}$, cruzaron el Ticino. Por otro lado, heredó de su hermano, entre otras cosas, prendas de vestir típicas de un hombre de $\operatorname{armas}^{38}$.

En 1637 Giovanni Pietro residía en aquella misma parroquia con Anna, mucho más joven que él, con quien muy posiblemente contrajo matrimonio en segundas nupcias, tras la muerte de su primera esposa con la que no había tenido hijos. Además, vivía con ellos, en la que figura en los registros parro-

32 RIZZO, 2012: 173-199.

3320 de junio de 1618, ASMi, Notarile, 26317.

34 Sólo Giovanni Ambrosio figura en un contrato suscrito por algunos armeros milaneses el 4 de octubre de 1619, ASMi, Notarile, 26132.

35 Stato dell'anime della Par[rocchi]a di S.ta Maria Seg[re]ta dell'anno 1631, ASDMi, VP, Santa Maria Segreta, 1566-1637, 2.

${ }^{36}$ Nota delli Battesimi fatti nella Parochia di S.ta Maria Secreta di Milano P.C. [...] dall'anno 1632 fino el [163]7, ASDMi, DSA, 59.

${ }^{37}$ En el texto que aparece a continuación, cuando cita a Crequi se refiere a François de Bonne-de-Créqui, duque de Lesdiguières y par de Francia: «[...] Vittorio Amedeo, ed il Crequì concentrarono le loro forze, ed a fine di divertire il nemico nel mese di giugno 1636 entrarono sul territorio di Novara, e si impossessarono di varie terre; quindi minacciando Vigevano passarono arditamente il Ticino, e la prima loro impresa fu di rompere le opere, per cui si conduce a Milano il naviglio, ciò che [...] obbligò il marchese di Leganés governatore, e comandante in capo l'armata spagnola ad avanzarsi col suo esercito, e presentar loro battaglia». BIFFIGNANDI BUCCELLA, 1810: 212.

38 «Calce e giupone di corame, berettino guarnito di passamano e bottoncini d'argento, [...] una spada indorata in una banda cremesile con pizi d'oro, una para di stivali di bulgaro inverso con speroni indorati, un paro de guanti longhi recamati d'argento et franza d'argento, due anelli con diamante, [...] un colare con pizi in ferraiolo di panno con bottoni d'argento [...], una fiaschettina da polvere, $[\ldots]$ una guardina di veluto ricamata di passamano [...] con coltello e folcelina d'argento, due bale da schiopo», 6 de noviembre de 1636, ASMi, Notarile, 30127. 
quiales como «2a casa del Borsano», su cuñada Clara, viuda de Giovanni Ambrosio, con las pequeñas Caterina y Vittoria Camilla, las dos hijas que le habían quedado tras la muerte precoz de la primogénita Vittoria Maria ${ }^{39}$.

En enero de 1639, Giovanni Pietro, con la calificación de «armorerius», fue el destinatario de un pago de 1.845 liras imperiales por 45 armaduras cuyo coste total era de 2.085 liras. Este pago formaba parte de un contrato mucho más amplio de suministro de 1.000 armaduras, suscrito poco antes con Giuseppe Moderati ${ }^{40}$, que era, de forma incidental, hermano de Barbara, esposa del Carlo Borsano citado al comienzo de este apartado.

\section{La familia Borsano: Carlo}

La figura de Carlo es hasta hoy bastante desconocida. Se sabe que, después de casarse en 1630, tuvo dos hijos: Prassede Maddalena, nacida a finales de octubre del año siguiente, y Pietro Ambrosio, con toda probabilidad «nuestro» Ambrosio, nacido los primeros días de octubre de 1633 y bautizado el 9 del mismo mes ${ }^{41}$. Posteriormente, en otro documento figura la estipulación a posteriori del acta de constitución de la dote para su boda que tuvo lugar el 19 de febrero de 1635 y en la que la esposa estuvo ausente ${ }^{42}$. Tanto la naturaleza del acta como la ausencia de la esposa a su firma sugieren que en esa época Barbara se encontraba gravemente enferma, circunstancia que nos permite suponer que habría muerto al poco tiempo. En aquel momento, el rastro de Carlo, por entonces aún residente en la parroquia de Santa Maria Beltrade, se pierde. Los registros de la parroquia del 27 de diciembre de 1650 indican que $^{43}$ Clara Riva, viuda y enferma, muere antes de cumplir 40 años ${ }^{44}$. También en este caso, teniendo en cuenta el estado actual de los estudios, la ausencia de ulteriores pruebas documentales impide llegar a conclusiones segu-

39 Stato delle Anime della cura di S.ta Maria Secreta del Anno 1637, ASDMi, VP, Santa Maria Segreta, 1566-1637, 2. Vittoria Maria, la primera hija de Clara y Giovanni Ambrosio, muerta sólo cinco días después del nacimiento, había sido sepultada en la iglesia de Santa Maria Segreta el 11 de septiembre de 1632, Morti dal $1^{\circ}$ gennaio 1586 al 26 dicembre 1639, ASPSMS.

4011 enero 1639, ASMi, Notarile, 30127. La estrecha relación entre la familia Borsano y la familia Moderati está demostrada por el hecho de que el padrino de bautismo de Caterina Borsano, hermana de Carlo, es Domenico Moderati; Note delli Battesimi fatti nella Parochia di S.ta Maria Secreta di Milano P.C. [...] dall'anno 1632 fino el [163]7, ASDMi, DSA, 59.

${ }^{41}$ Battesimi dal 1586 al 1639, ASDMi, PSMB.

42 ASMi, Notarile, 30127.

${ }^{43}$ Registro dei battesimi, dei matrimoni e dai morti dal 1647, ASDMi, PSMB.

4435 años de edad según el registro citado en la nota anterior; 38 según los status animarum de la parroquia de Santa Maria Segreta. 
ras. A partir de esta única noticia ${ }^{45}$ se puede suponer que Carlo, al encontrarse viudo y con dos hijos pequeños, decidió acoger a la esposa de su primo, hasta entonces huésped del cuñado Giovanni Pietro, que en un ya lejano mes de octubre había compartido con él la celebración de la boda en Santa Maria Beltrade y que, por entonces, se encontraba presumiblemente en su misma difícil condición ${ }^{46}$.

\section{La familia Borsano: Ambrosio}

Que (Pietro) Ambrosio, hijo de Carlo, sea efectivamente el Ambrosio Borsano «Ingeniero Mayor y Quartel Maestre General del Real Exército de Cattaluña», objeto de este estudio, constituye una hipótesis que, de momento, no puede demostrarse de forma irrebatible. Sin embargo, se basa en una serie, muy significativa, de circunstancias y evidencias documentales.

En primer lugar y ante todo, las fechas. La circunstancia de que Ambrosio naciera en Milán en octubre de 1633 es plenamente compatible y perfectamente coincidente con los otros hechos de su biografía conocidos. En particular, con su enrolamiento en el ejército en $1648^{47}$, al cumplir quince años de edad; con su participación, en 1655, cuando tenía 22 años, en tareas defensivas en el asedio de Pavía ${ }^{48}$; y con su traslado, en $1661^{49}$, ya cerca de los treinta años, a España.

En segundo lugar, no pueden pasar desapercibidas algunas recurrencias en los nombres de familia. De la misma manera que Pietro Ambrosio recibió los nombres de sus abuelos, Ambrosio Borsano y Giovanni Pietro Moderati, los hijos del Ambrosio Borsano español, Pedro Santos y Carlos José, recibieron los nombres de los antepasados del Ambrosio milanés: en el primer caso, de Giovanni Pietro Moderati con el homónimo «tío» Borsano, y en el segundo de Carlo Borsano con el tío materno Giuseppe Moderati.

${ }^{45}$ El dato no es confirmado por el registro de defunciones compilado por el Magistrado de sanidad: el 28 de diciembre de 1650 se registra sólo la muerte de Clara de Blancis, de 40 años, ASMi, Popolazione p.a., 125.

${ }^{46}$ El registro por parte del Magistrado de sanidad de Milán (ASMi, Popolazione p.a., 121) de la muerte de un Carlo «Besana» de 27 años ex percussione super caput del 20 de junio de 1635 en la parroquia de San Sátiro (confinante con la de Santa Maria Beltrade) deja abierta una ulterior hipótesis: que también Carlo haya muerto en los primeros años de vida de Ambrosio y que éste haya sido criado por la «tía» viuda, Clara Riva, quizás con la contribución del otro «tío», Giovanni Pietro, que, dadas las circunstancias, pasó a ser la figura de referencia de toda la familia Borsano.

47 AGMM, Colección Aparici, Papeles relativos a Don Ambrosio Borsano, tomo XL, 13-8, documentos 4.617-4.541.

48 RIZZO y MAZZOCCHI, 2000: 440.

${ }^{49}$ VIGANÒ, 2001: 151. 
Por último, el ambiente en el que creció y se formó el Ambrosio milanés. Éste frecuentó, sin duda, la familia de Moderati, comerciante de armas, pero también la de su socio comercial, Giovanni Pietro Borsano, pariente por vía paterna, soldado y, posteriormente, armero de discreta fama. Por otro lado, es preciso tener en cuenta que Giovanni Ambrosio, el hermano de Giovanni Pietro, era armero y quizás, en un segundo momento, también soldado. Mientras que Carlo Riva, que puede ser identificado, de forma plausible, como el hermano de Clara, esposa del mismo Giovanni Ambrosio, era bandera (alfiere) en el reparto de militares (terzo) de Porta Romana efectuado en julio de $1653^{50}$.

Todos ellos tuvieron sobre nuestro Ambrosio una fuerte influencia, orientándolo hacia el mundo militar, en el que - si es correcta la hipótesis que sostenemos-, pudo adquirir competencias cada vez más especializadas en el campo de la ingeniería, sobre todo durante los años que estuvo a las órdenes del maestro de campo general Gaspare Beretta.

\section{DE SOLDADO A AYUDANTE DE INGENIERO MILITAR: BORSANO Y LA GUERRA FRANCO-ESPAÑOLA EN EL NORTE DE ITALIA}

Las primeras actividades militares del joven Borsano tuvieron lugar, tal como se ha señalado, en 1648 cuando participó como mercenario a las órdenes del ingeniero militar Gaspare Beretta en el levantamiento del asedio de la ciudad de Cremona ${ }^{51}$. Desde entonces y hasta 1658 estuvo presente, primero durante cinco años como mercenario y después ya como soldado al servicio del rey de España en algunas de las principales actividades bélicas que tuvieron lugar en el norte Italia ${ }^{52}$. Un territorio que, entre el Tratado de Lyon de 1601 y el de los Pirineos de 1659, se convirtió en uno de los principales escenarios de la pugna secular entablada entre la Monarquía Hispánica y la Francesa por la hegemonía de Europa.

Durante este periodo tuvieron lugar en esta parte de Italia diversos enfrentamientos bélicos, cada uno de los cuales constituye un capítulo particular de esta magna lucha ${ }^{53}$. El último de estos capítulos se inició en 1635 cuando, a raíz de la intervención francesa en la Guerra de los Treinta Años, el rey de Francia Luís XIII declaró la guerra a la Monarquía Hispánica ${ }^{54}$. A partir de

507 de julio de 1653, ASMi, Registri delle Cancellerie dello Stato, XXI, 50.

${ }^{51}$ AGMM, Colección Aparici, Papeles relativos a Don Ambrosio Borsano, tomo XL, 1 3-8, documentos 4.617-4.541. RONCAI, 2007: 45.

52 AGMM, Colección Aparici, Papeles relativos a Don Ambrosio Borsano, tomo XL, 13-8, documentos 4.617-4.541. MARTÍ y ESPINO, 2013: 9.

${ }^{53}$ PARKER, 1985: 104-115. SIGNOROTTO, 1996: 25-32. PARROTT, 2006, vol. 1: 31 48. MAFFI, 2007: 9-12.

${ }^{54}$ BONNEY, 2003: 188-199. 
entonces, se sucedieron diferentes fases bélicas, alternándose los éxitos y los fracasos militares 55 .

En 1648, año de la incorporación de Borsano a la actividad militar, se inició una nueva fase de la guerra más favorable a los intereses de la Monarquía Hispánica. Este cambio se debió, básicamente, a dos hechos diferentes. El primero era que los españoles habían firmado, finalmente, ese año la paz con los protestantes holandeses, circunstancia que les permitió destinar al norte de Italia una parte de las fuerzas concentradas en los Países Bajos. Mientras que el segundo era que la Monarquía Francesa se vio muy afectada, entre 1648 y 1653, por una cruenta guerra civil: la Fronda. Un conflicto que le obligó a disminuir su intervención en el norte de Italia y a retirar una buena parte de los ejércitos que tenía en Cataluña. Como consecuencia de ello, en octubre de 1648 , los franceses se vieron obligados a levantar el asedio de Cremona. Fue esta la primera actividad bélica en la que, tal como se ha señalado, estuvo presente Borsano. Este revés militar francés fue acompañado, durante las campañas militares de 1649, 1650 y 1651, de una serie de ofensivas militares lanzadas sobre el Piamonte por los ejércitos de Felipe IV ${ }^{56}$. Por otro lado, a finales de 1650 , se consiguió recuperar Portolongone ${ }^{57}$. Aunque, la operación militar más destacada fue la conquista, en septiembre de 1652, de la fortaleza de Casale en el Monferrato, que se convirtió en la principal acción militar española en esta fase de la guerra. Acciones ambas en las que Borsano participó a las órdenes de Gaspare Beretta ${ }^{58}$.

Ahora bien, a partir de 1653, una vez resuelto el conflicto de la Fronda, la situación bélica experimentó un cambio radical. Los franceses iniciaron entonces una nueva fase de ofensivas militares en el norte de Italia. Así, en 1655, un poderoso ejército francés penetró profundamente en el territorio del estado de Milán y consiguió asediar, a finales de julio de ese año, la ciudad de Pavía. Sin embargo, las fuerzas dirigidas por los españoles lograron romper el asedio, en septiembre de 1655, obligando a los franceses y a sus aliados a retirarse ${ }^{59}$. Una operación exitosa en la que también participaron Beretta y Borsano.

Pavía fue, sin embargo, la última gran victoria de las fuerzas españolas. Un año más tarde, en junio de 1656, el ejército francés emprendió el asedio a la ciudad de Valenza, obteniendo su rendición dos meses más tarde. En 1657 los españoles intentaron recuperar, de forma infructuosa, esta ciudad, que permaneció en manos de los franceses. Una operación en la que, de nuevo, partici-

55 SIGNOROTTO, 1996: 26. ANGIOLINI, 2006: 171-188. MAFFI, 2007: 12-47.

${ }^{56}$ MAFFI, 2007: 49.

${ }^{57}$ ANGIOLINI, 2006, vol. 1: 186.

${ }^{58}$ AGMM, Colección Aparici, Papeles relativos a Don Ambrosio Borsano, tomo XL, 13-8, documentos 4.617-4.541. RONCAI, 2007: 45.

${ }^{59}$ RIZZO, 2000: 489. MAFFI, 2007: 55-56. 
paron Beretta y Borsano ${ }^{60}$. Por su parte, el ejército francés inicio ese mismo año un ataque contra la ciudad de Alessandria que resultó infructuoso y en el que, otra vez, encontramos tanto a Beretta como a Borsano ${ }^{61}$. Sin embargo, este contratiempo no detuvo las operaciones del ejército francés, ya que, en diciembre de 1657, lanzó una potente ofensiva contra el Ducado de Mantua, el último aliado que conservaba la Monarquía Hispánica en el norte de Italia. La ofensiva francesa alcanzó los objetivos marcados, logrando que, en julio de 1658, el duque de Mantua se declarara neutral. A partir de entonces, la defensa del Estado de Milán por parte de las fuerzas españolas se encontró en una situación particularmente difícil, ya que durante el verano de 1658 el ejército francés había conseguido llegar ya a muy pocos kilómetros de la ciudad de Milán ${ }^{62}$.

En ese momento, la situación general de la Monarquía Hispánica, que estaba en guerra no solo con Francia, sino también con Inglaterra y con los independentistas portugueses, era particularmente crítica. En junio de 1658 el ejército español de Flandes fue derrotado por una coalición franco-británica en la batalla de las Dunas y las operaciones bélicas que se estaban llevando a cabo para recuperar Portugal no acababan de lograr los objetivos persegui$\operatorname{dos}^{63}$. Como consecuencia de ello, los gobernantes franceses y españoles acordaron, entre otras cosas, en el Tratado de los Pirineos, firmado el siete de noviembre de 1659, la cesión de la fortaleza piamontesa de Pignerol a Francia y poner fin a las hostilidades en el norte de Italia ${ }^{64}$.

Fue durante el curso de estas actividades bélicas cuando Borsano conoció al que se convertiría en su maestro: el ingeniero militar Gaspare Beretta ${ }^{65}$. En una carta que Ambrosio Borsano escribió, en diciembre de 1695, explicaba, entre otras cosas, que había servido

... a Vuestra Magestad de 45 años a esta parte, sin cinco años que sirvió a su costa asistiendo a su maestro el maestro de campo Gaspar Bareta, ingeniero mayor en el Estado de Milán, habiendo servido en dicho ejército ${ }^{66}$.

De hecho, las relaciones que durante este período se forjaron entre ambos fueron determinante para la trayectoria militar de Borsano, ya que fue, enton-

\footnotetext{
${ }^{60}$ AGMM, Colección Aparici, Papeles relativos a Don Ambrosio Borsano, tomo XL, 13-8, documentos 4.617-4.541. RONCAI, 2007: 45.

${ }^{61}$ MAFFI, 2014: 151-152. AGMM, Colección Aparici, Papeles relativos a Don Ambrosio Borsano, tomo XL, 1-3-8, documentos 4.617-4.541. RONCAI, 2007: 45.

62 MAFFI, 2007: 57-63; 2014: 151-152.

${ }^{63}$ PARKER, 2006: 160.

${ }^{64}$ BÉLY, 2010, 18.

${ }^{65}$ RONCAI, 2007: 44-46.

${ }^{66}$ AGMM, Colección Aparici, Papeles relativos a Don Ambrosio Borsano, tomo XL, 13-8, documentos 4.617-4.541, 1695 p. 222.
} 
ces, cuando a las órdenes de Beretta aprendió las técnicas de la arquitectura y la cartografía militar ${ }^{67}$. Una relación que le permitió formar parte de la escuela milanesa de ingeniería militar y alcanzar en 1660 el grado de ayudante mi$\operatorname{litar}^{68}$.

\section{GaSPARE BERETTA Y LA ESCUELA DE INGENIERÍA MILITAR de MiLÁN}

\section{La profesión de ingeniero en Milán en la segunda mitad del siglo XVII}

Tal como lo ha señalado Francesco Repishti, el oficio de ingeniero militar era en aquella época una de las salidas profesionales que el arquitectoingeniero (hasta el siglo XVIII los términos «arquitecto» e «ingeniero» se utilizaban en Milán de forma indistinta) ${ }^{69}$ podía obtener en el Ducado. Por un lado, estaban los profesionales inscritos en el Colegio de arquitectos, ingenieros y agrimensores, llamados por ello collegiati $^{70}$, a los que se dirigían los particulares y los que dependían directamente de uno de los organismos responsables de la realización de las grandes obras de construcción de la ciudad (entre ellas el Duomo y el Ospedale Maggiore). Pero, por otro, estaban los arquitectos e ingenieros que, según la institución para la cual trabajasen, se llamaban ducali, regi, cesarei, porque eran los responsables de proyectar y ejecutar obras encargadas por la realeza; camerali, porque eran competentes en las obras del municipio, de la ciudad o de la sanidad (dependientes del tribunal homónimo); o militari porque eran responsables de obras del ejército ${ }^{71}$.

Una delimitación esquemática de las competencias que, al menos desde mediados del siglo XVI, distinguía a los ingenieros camerales de los militares puede hallarse en unas palabras de Giovanni Ambrogio Pessina, ingeniero cameral desde 1658. Estas palabras están reproducidas en las actas conclusivas redactadas en $1662^{72}$ de una larga disputa en torno a las respectivas tareas como consecuencia de la cual se encontraba, desde hacía años, enfrentado a Gaspare Beretta ${ }^{73}$, ingeniero militar desde 1647 y, más tarde, también regio

${ }^{67}$ AGMM, Colección Aparici, Papeles relativos a Don Ambrosio Borsano, tomo XL, 13-8, documentos 4.617-4.541, 1681, p. 178.

68 AGMM, Colección Aparici, Papeles relativos a Don Ambrosio Borsano, tomo XL, 13-8, documentos 4.617-4.541, 1681, p. 178. COBOS y CASTRO, 2005: 87-91.

${ }^{69}$ REPISHTI, 2007: 29, $\mathrm{n}^{\circ} 1$.

${ }^{70}$ Sobre los hechos relativos a la transformación, en 1603, de la Università degli ingegneri e agrimensori en el Collegio degli architetti, ingegneri e agrimensori véase la síntesis presentada en REPISHTI, 2007: 30, $\mathrm{n}^{\circ} 13$.

${ }^{71}$ REPISHTI, 2007: 23.

72 ASMi, Uffici Regi p.a., 745, cit. en REPISHTI, 2007: 26.

${ }^{73}$ Véase la ficha sobre Giovanni Ambrogio Pessina firmada por Francesco Repishti en BOSSI, LANGÉ y REPISHTI, 2007: 107-108. 
cameral. De forma muy resumida, puede señalarse, según Pessina, que, así como al ingeniero militar le competía únicamente el diseño de los fuertes y su delineación plantando los postes (piantando i paletti), como si se tratara de la intervención de un magistro a muro especializado, al ingeniero cameral se le pedía que visitara, estimara, probara y reconociera la obra que se estaba construyendo a expensas de la Cámara con competencias parecidas a las del extimator, el perito capacitado para realizar estimaciones y cómputos métricos ${ }^{74}$. La neta separación existente en la Lombardía entre los técnicos de los servicios militares y los del cuerpo cameral y civil representará, aún en 1755, un modelo para el imperio austríaco ${ }^{75}$.

En aquella época, las distintas formas en las que se expresaba la profesión de ingeniero en el Ducado de Milán —más allá de las diferencias, ya fueran leves o pronunciadas, de las competencias profesionales de cada una de ellas-, tenían en común el estatus de experto y, en consecuencia, una formación de carácter eminentemente práctica, en la que se imponía uno u otro tipo de ingeniero ${ }^{76}$. Así, en el caso de los arquitectos del Duomo y del Ospedale Maggiore aquella fase asumía los caracteres de una práctica con características «medievales», dirigida a formar un sucesor que fuera el responsable de la obra, incluso a través de la «revelación» de los intentos de los antiguos fundadores ${ }^{77}$ y la asunción de responsabilidades a partir de una plena adherencia formal a aquellos principios. Mientras que en el caso de los ingenieros militares, consistía en la adquisición, de forma progresiva, de la pratica di guerra con la experiencia directa en los campos de batalla; una competencia destinada a resultar más relevante $\mathrm{y}$, por tanto, discriminatoria entre quienes eran llamados a proyectar obras defensivas y quienes se limitaban a dirigir su ejecución.

En función de una u otra competencia específica, las vinculadas tradicionalmente a la figura del ingeniero - el diseño de estudio o de proyecto y el cómputo métrico-, eran: la delineación de los sitios en los que se pensaba construir una obra o de los elementos defensivos a consolidar; la representación de fuertes y ciudades, insertadas con esmero en su contexto geográfico para evidenciar los puntos fuertes y débiles; y - comprensiblemente en un número menor de casos-, la descripción de regiones completas, que por su naturaleza orográfica e hidrográfica constituían la base de extensos sistemas defensivos y de infraestructuras. Con el paso del tiempo, en el lecho común de la ingeniería militar se formaron dos especializaciones diferentes: la del ingeniero que debía afrontar personalmente, en virtud de una sólida experiencia práctica, las muchas cuestiones relacionadas con la guerra a través del

\footnotetext{
74 REPISHTI, 2007: 26-27.

75 REPISHTI, 2007: 26.

76 REPISHTI, 2007: 23.

77 REPISHTI, 2007: 24.
} 
proyecto en las diferentes escalas de las obras más modernas y eficaces; y la del ingeniero «topógrafo»" ${ }^{78}$ capaz de orientar el saber y las técnicas consolidadas hacia un conocimiento cada vez más territorial de los principales escenarios donde podía producirse una posible confrontación bélica.

El ya citado Gaspare Beretta fue capaz de actuar de forma diligente en ambas especializaciones. Enrolándose, en 1639, a los 16 años como simple soldado $^{79}$ supo adquirir rápidamente la experiencia y la autoridad que lo llevarían a desempeñar las funciones más prestigiosas y comprometidas no sólo en el ámbito profesional. Así, en el campo de la ingeniería militar fue nombrado ayudante de ingeniero en 1640 y, posteriormente, a finales de 1649, sucesor de Francesco Prestino con la calificación de ingeniero regio cameral ${ }^{80}$. Después, tras la exitosa dirección de las operaciones de defensa de Alessandria, en 1657, fue promovido al grado de ingeniero mayor y con posterioridad a 1663 encargado de la supervisión de todas las plazas del Estado de Milán, así como de las de Liguria en Final, Savona y Vado (ver figura 1). Como comandante militar fue nombrado sargento mayor en 1648 y, desde 1652, dirigió, entre otros, los asedios de Trino Vercellese, Crescentino, Casale. En el ámbito diplomático se le encargó, en 1673, una delicada misión en Grigioni. Mientras que en el político fue convocado, en 1661, a Madrid por la corte española ${ }^{81}$, al término del conflicto en la Lombardía, a coronamento di un decennio di eclatanti successi in tutto il teatro della guerra in Alta Italia para dar su opinión sobre el posible cambio, che si progettava del Monferrato del Sig. Duca di Mantova col Cremonese ${ }^{82}$ y que, al final, no llegó a materializarse.

La gran versatilidad y la igualmente marcada propensión a la acción, que se combinaban, compensándola, con la inicial formación teórica reducida a lo esencial $^{83}$ (de la que derivaría con el tiempo una sustancial indiferencia ante demostraciones de competencia emanadas de resultados concretos y de una lúcida y constante verificación), conferían a Beretta un perfil muy diferente y, en cierta forma, más moderno que el de personajes de un pasado aún reciente. En este sentido, basta pensar en el enfoque tradicional de la «práctica» militar

78 VIGLINO, 2005: 23.

7928 de diciembre de 1699, Beretta, Gaspare, Punti di Memoria toccanti alle Fortificationi delle Piazze di q.to Stato [...], BTMi, Belgioioso, 267, fasc. I, doc. 256.

${ }^{80}$ DE CARO, 1967, vol. 9.

81 1696, Beretta, Gaspare, Curiosa e sodisfattoria memoria, distesa dal Maestro di Campo Ingegnere mag.re Beretta, di come si trovano le Piazze di questo Stato di Milano [...], BTMi, Belgioioso, 267, fasc. I, doc. 275.

${ }^{82}$ Noviembre de 1696, Beretta, Gaspare, Servigi e memorie historiche del Conte e Maestro di Campo don Gaspare Beretta, BTMi, Belgioioso, 268, fasc. I, doc. 13.

${ }^{83}$ A la luz del precoz nombramiento a «ayudante de ingeniero» De Caro plantea la hipótesis de que Beretta habría adquirido de joven algún rudimento de matemáticas y de balística. DE CARO, 1967, vol. 9. 
FIgURA 1. Sitio y defensa de la Ciudad de Pavia.

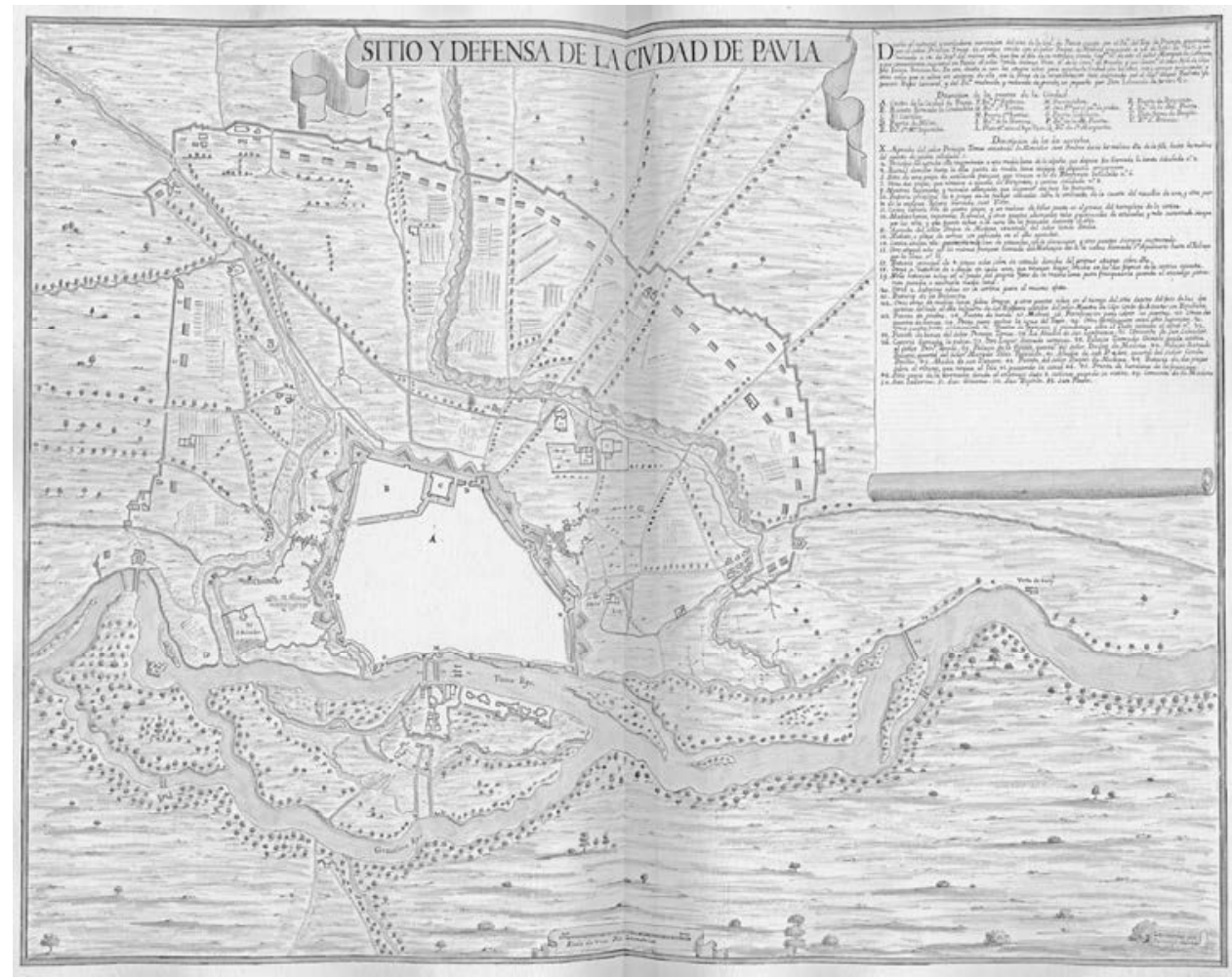

Gaspare Beretta, 1655, manuscrito, col. Copia reducida del original hecha por Leonardo di Ferrari ese mismo año.

Fuente: Riksarkivet (Estocolmo).

que realizaba Bernardo Ricchino ${ }^{84}$, que había nacido unos sesenta años antes que Beretta y que era ingeniero militar y cameral, titular de una academia, es decir, de una escuela pública de ingeniería militar y civil muy conocida en la ciudad y frecuentada no sólo por nobles milaneses sino también por varios capitanes españoles como Cristóbal Lechuga ${ }^{85}$. Ricchino, que, entre 1608 y 1611, intentó en vano ingresar en el Colegio de arquitectos, ingenieros y agrimensores de Milán ${ }^{86}$, un hecho que le parecía necesario para un pleno reconocimiento de su papel, fue una figura prestigiosa y emblemática de un

${ }^{84}$ Ver GATTI PERER, 2004.

${ }^{85}$ SCOTTI, 2003, vol. 2: 428.

${ }^{86}$ Véase la voz sobre Bernardo Ricchino firmada por Irene Giustina en BOSSI, LANGÉ y REPISHTI, 2007: 115-117. 
mundo profesional fundado sobre un conocimiento, ante todo, abstracto, que estaba destinado a experimentar un profundo cambio ${ }^{87}$.

A la muerte de Prestino, Gaspare Beretta, formado a su lado en los campos de batalla, ganó un litigio que mantenía con otro profesional milanés: el hijo del ingeniero militar Bernardo Ricchino, Francesco Maria Ricchino, que sólo poseía el título de ingeniero colegiado y cameral y que había sustituido a Prestino tras su fallecimiento en las obras de los fuertes de Novara y Mortara. Además, en 1652, logró comprar a la viuda de éste todos los papeles del que fuera su predecesor y maestro ${ }^{88}$. Unos papeles que le eran de gran valor no sólo desde el punto de vista afectivo, sino también, y sobre todo, a la luz de su doble calificación de ingeniero militar e ingeniero regio cameral, por ser relevantes ejemplos de referencia profesional.

\section{Gaspare Beretta y Ambrosio Borsano}

La cercanía a Gaspare Beretta orientó, de manera decisiva, la primera parte de la vida de Ambrosio, que posteriormente recorrería fielmente la carrera de su maestro. A su lado conoció, de forma personal, muchos escenarios de guerra y aprendió las técnicas defensivas y obsidionales más avanzadas de la época. Asistiéndole en la profundización de los detalles ejecutivos y, aún más, de los mapas de encuadramiento y en la verificación de las obras a realizar, Borsano conoció y asimiló una eficaz modalidad de representación cartográfica de las arquitecturas militares, del territorio y del paisaje circundante.

Para los gobernadores españoles de Milán, la defensa del estado dependía de un conocimiento puntual y constantemente actualizado de todo el recinto amurallado de las ciudades y de las fortalezas para dominar los puntos estratégicos. Unos puntos que como los eslabones de una cadena van encerrando la mayor parte de los límites del Estado ${ }^{89}$ a lo largo de las principales fronteras en su mayoría de carácter fluvial: la frontera con el Piamonte saboyano, cada vez más vinculado a la corte francesa y la frontera con la república de Venecia. Los numerosos ingenieros militares de diferente origen que estaban activos a comienzos del siglo XVII en el Estado de Milán y que se dedicaban de forma simultánea a la guerra y a la gestión de las estructuras defensivas de

87 Así, se proponía al rey de España para instruir a otros o porgere intelligenze delle teoriche con le pratiche loro y no viceversa. GATTI PERER, 2004: 24.

${ }^{88}$ SCOTTI, 2003, vol. 2: 426.

89 «[...] quasi anelli di una catena si vanno incatenando, et collegando l'un l'altro, et richiudendo la più parte dei confini dello Stato», Busca, Gabrio, Descritione delle fortezze di frontera dello Stato di Milano, s.d. [1600-1602], BCBPv, ms. II, 59. Citado en SCOTTI, 2003: 465 n $^{\circ} 3$ y en DAMERI, 2013: 61. 
todo el estado solicitaban para Madrid reconocimientos geográficos que fueran acompañados de detalladas descripciones del relieve ${ }^{90}$.

En respuesta a tal exigencia, alrededor del año 1600, Gabrio Busca, que era capitán de artillería y que había sido llamado a Milán por el gobernador Juan Fernández de Velasco, redactó la célebre Descritione delle fortezze di frontera dello Stato di Milano ${ }^{91}$. Mientras que el ingeniero Francesco Prestino visitó y diseñó en 1633 todas las fortalezas y ciudades del Estado. De esta manera, se renovó un modus operandi, inaugurado en los años 1546-47 por Giovanni Maria Olgiati, ingeniero militar y capitán de la artillería, que durante varios años estuvo al frente de los ingenieros militares de la Lombardía, con el detallado estudio de las necesidades de fortificación de todo el estado dispuesto por Ferrante Gonzaga, nuevo gobernador milanés. Eran los años cruciales de la entrada definitiva del estado de Milán en la órbita imperial, después de la muerte prematura, acaecida en 1545, del segundogénito de Francisco I, Carlos de Valois, duque de Orleáns, ante el que Carlos V se había demostrado dispuesto a ceder el estado de Milán y la Borgoña a cambio de su boda con una descendiente de la casa de Habsburgo y del fallecimiento en 1546 de Alfonso III de Ávalos, hasta aquel momento jefe del ejército del Sacro Imperio Romano Germánico en Italia ${ }^{92}$.

La necesidad de mantener informada una corte «lejana» ${ }^{93}$ acerca de la localización y la consistencia de todo el sistema defensivo del Estado de Milán, que era considerado la llave de Italia y el corazón de la Monarquía por su posición de enlace entre la aliada república de Génova y los territorios imperiales y los dominios de Flandes a través de los pasos alpinos de la Valtellina y la Valchiavenna, cuyo transito estaba garantizado mediante una serie de acuerdos precisos con las ligas suizas y los Grigioni, fue el factor que originó, de hecho, la precocidad y los rasgos de originalidad que distinguen la práctica de los principales ingenieros militares lombardos, a pesar de la convencionalidad de las técnicas de representación cartográficas adoptadas ${ }^{94}$. En este sentido, es preciso señalar que este factor fue, en realidad, más importante que las finalidades declaradas o las disposiciones emanadas de una institución específica promovida por la corte.

90 SCOTTI, 2003, vol. 2: 426.

${ }^{91}$ SCOTTI, 2003, vol. 2: 424.

92 Véase la voz sobre Giovanni Maria Olgiati firmada por Silvio Leydi en BOSSI, LANGÉ y REPISHTI, 2007: 95. LEYDI, 1989.

93 SCOTTI, 2003, vol. 2: 424.

94 Ver VIGLINO, 2005. 


\section{La confrontación con el Estado saboyano}

En el cercano estado saboyano, después de la elección definitiva en 1652 de Turín como capital, preferida no sólo en Chambéry sino también en Niza y en Vercelli, y del nacimiento ese mismo año del heredero masculino de la Casa Saboya, Carlo Emanuele, así como ante la oportunidad para los príncipes de Piamonte de llevar a cabo una política autónoma más incisiva ${ }^{95}$, se registraban tendencias análogas, aunque eran fruto de exigencias en buena medida diferentes. Allí se exigía la elaboración de una representación cartográfica actualizada del conjunto de todo el territorio ducal con el fin de dar una imagen fiable de las fronteras y de la localización de las muchas fortalezas erigidas para su defensa.

Este era el caso de los aproximadamente novecientos castillos existentes entonces, que constituían una red tan densa que a los observadores extranjeros les parecía imposible dar tan sólo quattro passi sin que se ne scuoprano tre o quattro ${ }^{96}$, de manera que la ausencia de una continuidad territorial efectiva exigía un conocimiento exhaustivo de la línea fronteriza y de sus numerosos puntos críticos. No por casualidad, Carlo Morello al recordar, en 1656, en la dedicatoria a Carlo Emanuele Filiberto Giacinto Simiana, marqués de Pianezza, los objetivos que lo llevaron a la redacción de sus Avvertimenti sopra le fortezze di S.A.R. ${ }^{97}$, afirma haber expresado, de forma diligente,

\footnotetext{
...con colori $[\ldots]$ non solo tutte le fortezze dello Stato della medesima A.R., ma de' vicini ancora, girando l'occhio curioso atorno a' confini di quello, per far conoscere che pregiudicio, che ostacoli, che opportunità l'une all'altre citta apportino, dando insieme a' Principi, e a Generali d'eserciti brevi osservationi per assedij, per soccorsi, per espugnatione, per diffese delle delineate fortezze ${ }^{98}$.
}

Desde esta perspectiva, su representación cartográfica de la ciudad de Vigevano, que había podido conocer personalmente en 1646 tras la expugnación de esta plaza fuerte cuando se encontraba al servicio del príncipe Tommaso Francesco de Saboya, resulta particularmente detallada no sólo en relación a las forme e misura delle mure, sino a la relación existente entre la ciudad y el territorio circundante con el levantamiento cartográfico de las puertas, los alojamientos para soldados y caballos, la posición de las cisternas, los pozos y los depósitos para la munitione da guerra ${ }^{99}$.

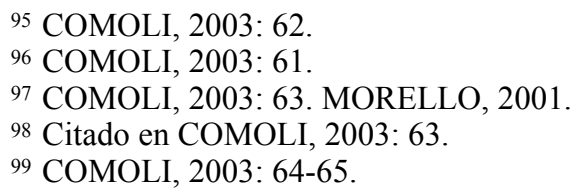


La empresa de Morello tendrá una continuidad ideal en la igualmente imponente obra del topógrafo y cartógrafo Tommaso Borgonio. Este que, entre 1673 y 1680, se encontraba al servicio del duque Carlo Emanuele II, de la dama real Maria Giovanna Battista de Saboya Nemours y del joven Vittorio Amedeo II ${ }^{100}$, estuvo ocupado durante esos años en la preparación de un mapa general de los Estados saboyanos (de' Stati di S.A.R.) (figura 2), en los estudios topográficos necesarios para la ilustración del Theatrum Sabaudiae, así como en el diseño de un mapa geográfico del Piamonte para el editor de Ámsterdam Joan Blaeu.

FIGURA 2. Hoja 4 de la Carta corografica degli Stati di S.M. il re di Sardegna [...]

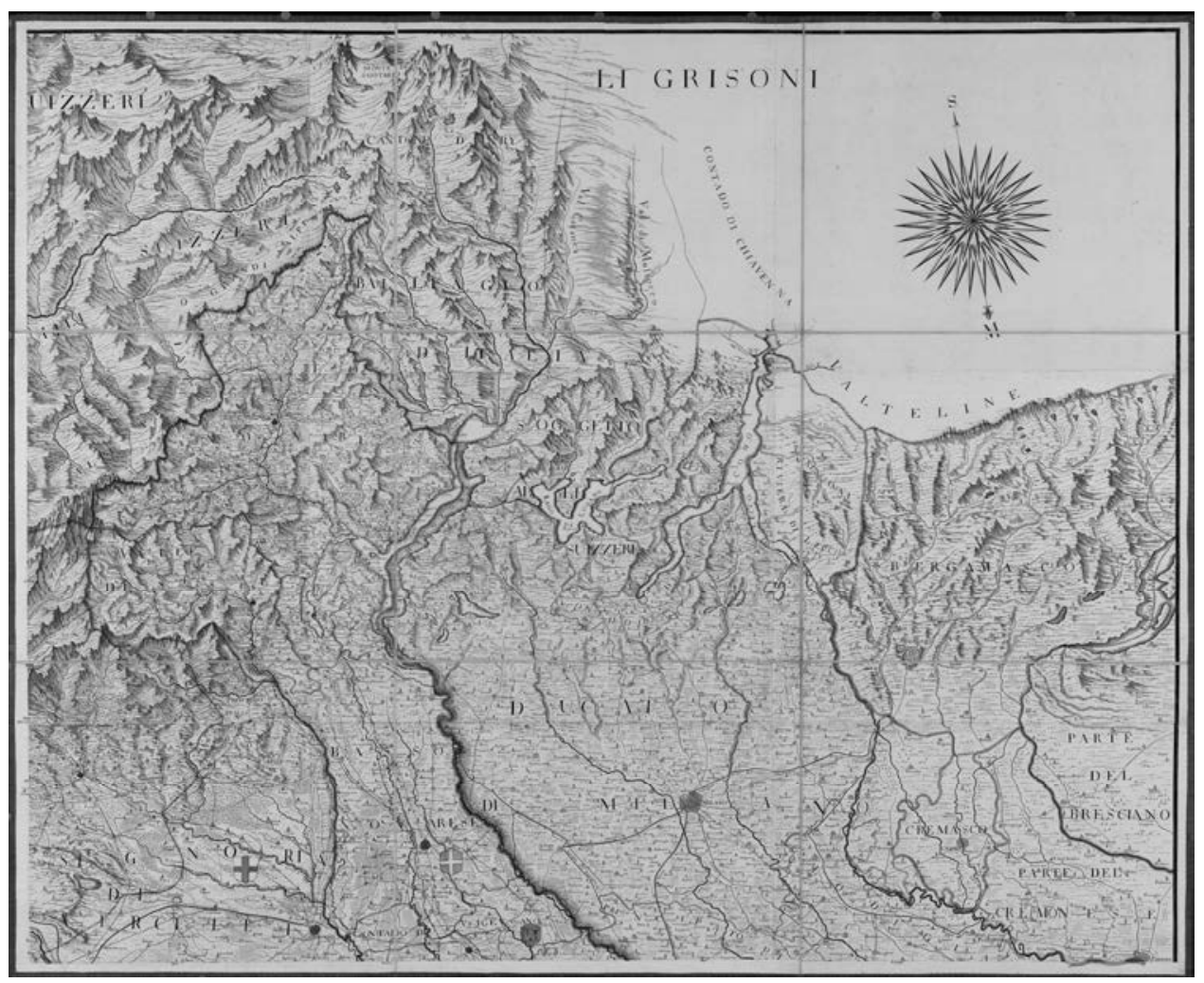

Giovanni Tommaso Borgonio, 1683, grabado en 1722 por Jacopo Stagnon a partir del mapa original de 1683.

Fuente: Archivio di Stato di Torino (Turín).

${ }^{100}$ GENTILE, 1981: 112. 
La técnica del diseño, así como los símbolos adoptados en la clasificación rigurosamente jerárquica de los núcleos de población, caracterizados, a lo sumo, con la esquematización de las principales estructuras defensivas y la red viaria reducida a grafo vial esencial, sitúan los mapas de Morello, primero, y los de Borgonio, después, en la senda de una producción cartográfica de aquella época muy consistente. Una senda cuyos pioneros y epígonos son - incluso por efecto de los frecuentes momentos de cercanía entre los Saboya y la corona española - , tanto piamonteses como lombardos. En efecto, es verdad, por un lado, que, tal como lo acabamos de señalar, las representaciones cartográficas generales del estado saboyano y las del estado milanés derivaban de motivaciones en parte diferentes y que, por el otro, en la corte de Turín — que, es preciso no olvidar, estaba siempre al límite de la subsistencia económica-, el proceso de especialización topográfica de los ingenieros, en términos de institucionalización de su formación y actividad profesional, recibió atención sólo en el siglo XVIII con la creación del Ufficio di topografía reale y de las Scuole teoriche e pratiche di artiglieria ${ }^{101}$. Una especialización que en el caso del Ducado de Saboya también desciende a ese punto por una generalizada, y casi de forma disciplinaria, transferencia con cambio de objeto y de escala del estudio o de la representación gráfica de la fortificación al territorio, cual hipotético escenario de enfrentamientos armados ${ }^{102}$.

Sin embargo, es igualmente cierto que Francesco Paciotto, originario de Urbino, poco después de haber sido nombrado en 1561 ingeniero mayor del Estado de Milán, durante su estancia en el Piamonte, donde había trabajado durante los años 1564 y 1566, entre otras cosas, en el proyecto de la ciudadela de Turín, que fue la primera planta pentagonal regular de Europa ${ }^{103}$, había redactado los proyectos de muchas fortificaciones saboyanas de frontera ${ }^{104}$. Así, como el hecho de que, desde 1574, el ingeniero lombardo Gabrio Busca

101 VIGLINO, 2005: 17.

102 FRANCHINI, 2007: 122. Franchini, en particular, asocia la evolución de la función del ingeniero militar a la figura de Giuseppe Francesco Ignazio Bertola (1676-1755), ya que fue de los primeros en intuir y teorizar que la ocupación preeminente del ingeniero militar al servicio de la corte, hasta entonces dedicado principalmente al diseño de fortificaciones, seguiría inevitablemente la dirección de la representación topográfica: el ingeniero militar del diseño de la «máquina de guerra» tenía que hacerse cargo definitivamente de prefigurar las «geografías de guerra». Sobre Ignazio Bertola, primer ingeniero del rey, véase también: VIGLINO, 2005. Sobre el paso progresivo y generalizado de la formación europea de los ingenieros militares de modalidades corporativas a otras más rigurosas, consecuencia primero del paso del arte de la fortificación de ciencia «individual» a ciencia «compartida» bajo la égida abstracta del estado moderno. Véase VIGANÒ, 2001: 154-155.

${ }^{103}$ Véase la ficha sobre Francesco Paciotto firmada por Marino Viganò en BOSSI, LANGÉ, REPISHTI, 2007: 97 y ss.

104 Véase la ficha sobre Francesco Paciotto firmada por Antonella Perin en VIGLINO, CHIODI, FRANCHINI y PERIN, 2008: 189-192. 
había desempeñado un papel fundamental en la definición del proyecto defensivo di qua e de la da monti impulsado por Emanuele Filiberto y continuado por su hijo Carlo Emanuele I ${ }^{105}$. De la misma manera que, unos años más tarde, Ercole Negro de Sanfront había contribuido, de forma notable, a la proyección del sistema fortificado en la defensa de los valles alpinos, realizando detalladas inspecciones y estudios documentales a partir de diseños de los sitios más adecuados para acoger nuevas estructuras defensivas en el Valle Stura y en la Val Varaita ${ }^{106}$. Y que, al terminar el siglo XVI, Carlo Vanello había llevado a cabo un detallado reconocimiento de los territorios situados entre la Val Vermenagna y el mar ${ }^{107}$.

Precisamente, los complejos, y a veces casi inverosímiles, hechos políticos, situados sobre el fondo de los acontecimientos del último cuarto del siglo XVII aquí citados, concurrieron a entrelazar las biografías y a hacer aún más híbridas las ya débiles especificidades de las distintas realidades regionales. Unas especificidades destinadas a acentuarse sólo con la institución de verdaderas escuelas ${ }^{108}$. En este sentido, basta pensar que mientras las cortes de Turín y Lisboa negociaban las bodas del «recalcitrante» Vittorio Amedeo II con la infanta Elisabetta Luisa Giuseppa, que era sobrina de la dama real por parte de la hermana, el duque otorgaba al secretario de estado Borgonio una dádiva de 870 liras per l'opera geografica de'stati nostri che fa in pittura per mandare in Portogallo. Una obra que era, tal como lo sugirió Guido Gentile, una especie de traducción ostentosamente colorida, según el gusto de Borgonio, miniaturista de libros de ballet, de la Carta generale de' Stati di S.A.R., quizás con aspecto de atlas, o de otra elaboración análoga del secretariocartógrafo en función celebrativa de la casa real ${ }^{109}$.

A su vez, Gaspare Beretta, en la cumbre de su carrera y a punto de convertirse en el máximo responsable del sistema defensivo del Estado milanés, se dirigió a España, chiamato, et honorato da Sua Maestà ${ }^{110}$, acompañado por

105 Véase la ficha sobre Gabrio Busca firmada por Elisabetta Chiodi en VIGLINO, CHIODI, FRANCHINI y PERIN, 2008: 77-79. Del estudio, realizado con el fin de identificar el potencial defensivo y ofensivo del tramo de valle de Dora Riparia de Monginevro a Susa y atribuido a Busca, que visto en su conjunto puede confundirse con una representación de paisaje de excepcional vivacidad, Micaela Viglino notaba que un examen detallado revelaba todo el potencial de un instrumento de verificación preliminar a acciones militares, documentado con el diseño y con las anotaciones escritas. Véase VIGLINO, 2005: 24.

106 Véase la ficha sobre Ercole Negro, conde de Sanfront, firmada por Elisabetta Chiodi en VIGLINO, CHIODI, FRANCHINI y PERIN, 2008: 181-183.

107 Véase la ficha sobre Carlo Vanello firmada por Elisabetta Chiodi en VIGLINO, CHIODI, FRANCHINI y PERIN, 2008: 263-264.

108 VIGLINO, 2005: 9.

${ }^{109}$ GENTILE, 1981: 120.

110 1696, Beretta, Gaspare, Curiosa e sodisfattoria memoria, distesa dal Maestro di Campo Ingegnere mag.re Beretta di come si trovano le Piazze di questo Stato di Milano [...], BTMi, Belgioioso, 267, fasc. I, doc. 275. 
Ambrosio Borsano — que así entra en el segundo y más importante capítulo de su vida profesional- , de Geronimo Rinaldi y de otros ingenieros militares lombardos, tal como se explicará más adelante. Posteriormente, tras los años oscuros de la acusación infamante de haber pagado a diversos empresarios algunos edificios mal construidos (abbonate all'Impresarij alcune fabriche da essi mal lavorate) $)^{111}$, del proceso a que fue sometido y de su reclusión, entre 1679 y 1684 , en el castillo milanés ${ }^{112}$ y a raíz de la estrecha alianza de Vittorio Amedeo II, que se encontraba muy presionado por Luis XIV, con la Corona española en el marco de la Guerra de los Nueve Años, también conocida como de la Liga de Augusta ${ }^{113}$, prestó durante más de una década servicio al duque de Saboya, obteniendo como premio la concesión del feudo de Ceva en Cuneo ${ }^{114}$.

La lectura de las plantas de la fortaleza de Hostalric y de la ciudad de Tarragona conservadas en el fondo Belgioioso de la Biblioteca Trivulziana de Milán permite ver ecos por ahora vagos - cuya veracidad aún debe corroborarse y ser considerada con la máxima cautela-, de la pertenencia de los ingenieros topógrafos de la época, sobre todo si son de idéntica procedencia, a un ambiente profesional común, independientemente de su contingente militancia a favor de uno $\mathrm{u}$ otro «partido» activo en la mutable escena europea de la época ${ }^{115}$. Estas plantas, de trazo rápido y esencial, como si se tratara de estudios veloces por su extensión y por los elementos representados, evocan directamente las imágenes de tema análogo contenidas en la colección ${ }^{116}$ de planos considerados preparatorios para el gran mapa de Cataluña que Ambrosio Borsano firmó en 1687, ya sea entre las plantas y vistas de ciudades y fortalezas dispuestas en el marco de este mapa; ya sea en el Atlas Medici de Lorenzo Possi ${ }^{117}$. Sin querer enfatizar tales referencias más de lo debido, ya que somos muy conscientes de que en aquella época era muy común la práctica de copiar los dibujos existentes 118 y de que el fondo Belgioioso ha experimentado grandes reorganizaciones y desmembramientos ${ }^{119}$, resulta innegable, de todas maneras, que semejante sugestión exige ulteriores verificaciones y profundizaciones.

11117 de marzo de 1681, BTMi, BELGIOIOSO, 268, fasc. 118.

112 Noviembre de 1696, Beretta, Gaspare, Servigi e memorie historiche del Conte e Maestro di Campo don Gaspare Beretta [...], BTMi, Belgioioso, 268, fasc. I, doc. 13.

113 CHIODI, 2005: 63.

114 CHIODI, 2005: 72.

${ }^{115}$ BTMi, Belgioioso, 270, fasc. II, doc. núm. 166 y 172.

$116 \mathrm{BNE}, \mathrm{mss} / 12683$.

117 POSSI, 2014.

118 VIGLINO, 2005.

${ }^{119}$ FIOR y VIGANÒ, 2002. 


\section{DE UN FRENTE MILITAR A OTRO}

En 1660, una vez pacificado el frente del norte de Italia, la carrera militar de Borsano realizó un giro que cambiaría su vida: su traslado a la península Ibérica, donde permanecía activo el conflicto abierto, en diciembre de 1640, entre los independentistas portugueses y la Monarquía Hispánica. Este conflicto, que entró en una fase de parálisis en 1643 y que permaneció aletargado durante unos cuantos años, volvió a activarse en 1656 a raíz de la muerte sin descendencia del rey portugués João $\mathrm{IV}^{120}$. Así, en 1657, los españoles pusieron sitio y tomaron las poblaciones portuguesas de Olivenza y Mourão, al tiempo que consiguieron romper el asedio portugués a la ciudad de Badajoz. Durante el año siguiente, el 1658, la Monarquía Hispánica lanzó un potente ejército contra la ciudad de Elvas, pero los portugueses lograron derrotarlo en enero de 1659.

Unos meses más tarde, en mayo de 1659, ante la inminencia de las negociaciones políticas que darían lugar al Tratado de los Pirineos, la Monarquía Hispánica acordó suspender estas actividades bélicas. Precisamente, uno de los objetivos perseguidos en este tratado por los negociadores españoles era que la monarquía francesa no apoyará la causa de los independentistas portugueses $^{121}$. Una vez logrado este acuerdo, los gobernantes españoles reactivaron, de forma inmediata, los planes de conquista de Portugal. A fin de hacerla efectiva, en 1660, se nombró a Juan José de Austria «capitán general de la conquista de Portugal»y, con gran celeridad, se trasladaron al frente portugués tropas desde Flandes, Italia y diferentes partes de España ${ }^{122}$.

Así, entre 1660 y 1668, se destinaron a este frente unos 20.000 soldados italianos, de los que 7.299 procedían del Estado de Milán ${ }^{123}$. Una movilización que formaba parte, según Henry Kamen, de la estrategia militar seguida por el imperio español desde sus orígenes ${ }^{124}$. Y que, según Antonio José Rodríguez Hernández, obedecía básicamente, a tres factores: a la desmovilización del ejército en Milán a raíz del Tratado de los Pirineos; al pensamiento militar de la época que consideraba que un soldado era más eficaz cuanto más lejos se encontraba de casa, ya que esta circunstancia incrementaba tanto su combatividad como su fidelidad; $y$, al hecho de que los soldados italianos eran los más apreciados por el alto mando español ${ }^{125}$.

Uno de los muchos militares italianos que entonces fueron destinados a la península Ibérica para hacer realidad el plan trazado para recuperar Portugal

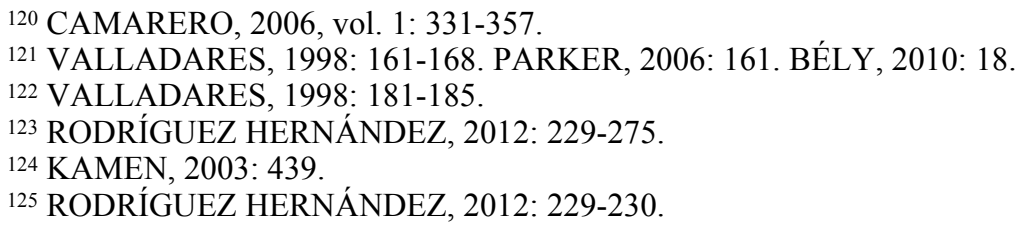


fue Ambrosio Borsano. El 30 de junio de 1660, el entonces gobernador y capitán general del Estado de Milán, Francesco Caetani, duque de Sermoneta, aprobó una relación de ingenieros militares lombardos que tenían que ser enviados a España. En esta relación, en la que aparece el nombre de algunos de estos militares, su cargo y el sueldo asignado, se menciona a Ambrosio Borsano. La relación viene encabezada por Gaspare Beretta, teniente de maestro de campo general e ingeniero mayor con un sueldo asignado de $1.015,9$ escudos. A continuación, se indica el nombre de tres ingenieros militares: Giuseppe Selar, Pedro Rugero (Pietro Ruggiero) y Gerónimo Reynaldi (?-1681) con un sueldo medio de 500 escudos. Y, por último, aparece el nombre de cuatro ayudantes de ingeniero militar, uno de los cuales es Ambrosio Borsano, con un sueldo asignado de 200 escudos $^{126}$.

La orden del duque de Sermoneta pone de manifiesto como Ambrosio Borsano formaba parte del equipo de ingenieros militares lombardos de confianza que mandaba Gaspare Beretta. Su ejecución tuvo, sin embargo, una incidencia diferente para ambos militares. Así, mientras Beretta consiguió volver inmediatamente a Milán, para Ambrosio Borsano se abrió una nueva etapa de su vida como ingeniero militar que le alejaría, de forma definitiva, de su ciudad natal. Borsano llegó a Extremadura, junto con los ingenieros militares Reynaldi y Ruggiero, durante el verano de $1661^{127}$. A partir de entonces y hasta 1668, participó en algunas de las principales operaciones bélicas llevadas a cabo por el ejército de Extremadura a fin de intentar reconquistar el reino de Portugal ${ }^{128}$. Fue entonces, fruto de estas actividades militares, cuando Borsano empezó a trazar los primeros planos de fortalezas y ciudades ibéricas que se le conocen ${ }^{129}$.

\section{CONCLUSIONES}

La investigación llevada a cabo permite indicar que Ambrosio Borsano nació en Milán en octubre de 1633 en el seno de una familia de armeros, alguno de cuyos miembros ejerció la profesión de soldado. El joven Borsano frecuentó la familia de Giuseppe Moderati, comerciante de armas, así como la de Giovanni Pietro Borsano, un pariente cercano suyo que fue soldado y armero.

En 1648, siguiendo los pasos emprendidos por otros miembros de su familia, Borsano inició sus actividades militares en el levantamiento del sitio de la ciudad de Cremona como mercenario. A partir de ese año y hasta 1658 inter-

${ }^{126}$ AGS, Guerra y Marina, legajo 3.378.

127 SÁNCHEZ, SÁNCHEZ y TESTÓN, 2014: 44.

128 VALLADARES, 1998: 185-199.

129 TESTÓN, SÁNCHEZ y SANCHÉZ, 2003: 17-18; 2009. SÁNCHEZ, SÁNCHEZ y TESTÓN, 2014. 
vino en algunas de las principales actividades bélicas que tuvieron lugar en el norte de Italia como consecuencia de la pugna secular entablada entre la Monarquía Hispánica y la Corona francesa por la hegemonía de Europa.

En la mayor parte de estas actividades también participó el ingeniero militar Gaspare Beretta que se convirtió en su maestro. Fue entonces cuando el joven Borsano, que en muchos aspectos seguiría la trayectoria profesional de Beretta, aprendió la profesión de ingeniero militar. Su maestro, que había sido discípulo del ingeniero militar Franceso Prestino muerto en 1648 justamente durante el asedio de Cremona, fue nombrado ayudante de ingeniero en 1640. Más tarde, en 1649, obtuvo el título de ingeniero regio cameral y en 1657, tras la exitosa dirección de las operaciones de defensa de Alessandria, fue nombrado ingeniero mayor del ejército del Estado de Milán.

Los múltiples conocimientos teóricos y prácticos de Beretta le permitieron operar con gran diligencia en los diversos ámbitos de actuación de la ingeniera militar de la época y, muy particularmente, en el de la cartografía. Una actividad que se encontraba entonces en pleno desarrollo y que no estaba circunscrita, como mínimo, en el norte de Italia a unos rígidos marcos regionales. El hecho de que el mismo Beretta trabajara durante más de una década al servicio del duque de Saboya pone de relieve las intensas y estrechas relaciones cartográficas existentes a lo largo del siglo XVII entre el estado de Milán y el estado saboyano.

En 1660, una vez pacificado el norte de Italia tras la firma del Tratado de los Pirineos, Beretta fue destinado a la península Ibérica junto a un grupo de ingenieros militares lombardos que se encontraban a sus órdenes. Entre estos ingenieros cuya misión principal era participar en la guerra emprendida por la Monarquía Hispánica para recuperar Portugal se encontraba un ayudante de ingenieros llamado Ambrosio Borsano. Su traslado, que se hizo efectivo en 1661, formaba parte de la tradicional estrategia imperial de la Monarquía Hispánica de utilizar en diferentes frentes soldados y militares procedentes de los diversos territorios que estaban bajo su gobierno. Su llegada a la península Ibérica dio lugar a una importante transferencia tecnológica, ya que contribuyó a difundir en España las técnicas de la cartografía militar vigentes en el Estado de Milán a mediados del siglo XVII.

\section{BiBLIOGRAFÍA}

Alfaro Guixot, Joan Manuel, Dues hores al castell de Cardona, Girona, Edicions les Fortaleses Catalanes, 2011.

Angiolini, Franco, «I Presidios di Toscana: cadena de oro e llave y freno de Italia», en Enrique García Hernán y Davide Maffi (eds.), Guerra y Sociedad en la Monarquía Hispánica: política, estrategia y cultura en la Europa moderna (1500- 
1700) vol. 1, Madrid, Ediciones del Laberinto/Fundación Mapfre/CSIC, 2006: 171-188.

Bély, Lucien, «Westphalie, Pyrénées, Utrecht: trois traités pour redessiner l'Europe», en Òscar Jané (ed.), Del Tractat dels Pirineus a l'Europa del segle XXI: un model en construcció, Barcelona, Museu d'Història de Catalunya, 2010: 13-21.

Biffignandi Buccella, Pietro Giorgio, Memorie istoriche della citta e contado di Vigevano [...], Vigevano, Tipografia di Vigevano, 1810.

Bonney, Richard J., «La guerra de diversión de Francia», en Geoffrey Parker (ed.), La Guerra de los Treinta Años, Madrid, A. Machado Libros, 2003: 188-199.

Bossi, Paolo, Langé, Santino y Repishti, Francesco, Ingegneri ducali e camerali nel Ducato e nello Stato di Milano (1450-1706). Dizionario biobibliografico, Florencia, Edifir, 2007.

Branach, Jordan, The Cartographic State. Maps, Territory, and the Origins of Sovereignity, Cambridge, Cambridge University Press, 2015.

Buisseret, David, La Revolución cartográfica en Europa, 1400-1800, Barcelona, Paidós, 2004.

Buisseret, David, «Spanish Peninsular Cartography, 1500-1700», en David Woodward (ed.), The History of Cartography. Vol. 3. Cartography in the European Renaissance. Parte 1, Chicago, The University of Chicago Press, 2007a: 1069-1094.

Buisseret, David, «French Cartography: The ingenieurs du roi, 1500-1650», en David Woodward (ed.), The History of Cartography. Vol. 3. Cartography in the European Renaissance. Parte 1, Chicago, The University of Chicago Press, 2007b: 1504-1521.

Cámara, Alicia, «Esos desconocidos ingenieros», en Alicia Cámara (ed.), Los ingenieros militares de la Monarquía Hispánica en los siglos XVII y XVIII, Madrid, Ministerio de Defensa, 2005: 13-29.

Camarero Pascual, Raquel, «La Guerra de Recuperación de Cataluña y la necesidad de establecer prioridades en la Monarquía Hispánica (1640-1643)», en Enrique García Hernán y Davide Maffi (eds.), Guerra y Sociedad en la Monarquía Hispánica: política, estrategia y cultura en la Europa moderna (1500-1700), vol. 1, Madrid, Ediciones del Laberinto/ Fundación Mapfre/CSIC, 2006: 305-322.

Chiodi, Elisabetta, «Prime annotazioni sull'attività piemontese di Gaspare Beretta ingegnere militare dello Stato di Milano», en Angela Marino (coord.), L'architettura degli ingegneri. Fortificazioni in Italia tra '500 e '600, Roma, Gangemi editore, 2005: 63-76.

Cobos Guerra, Fernando, Castro Fernández, José Javier de, «Los ingenieros, las experiencias y los escenarios de la arquitectura militar española en el siglo XVII», en Alicia Cámara (coord.), Los ingenieros militares de la Monarquía Hispánica en los siglos XVII y XVIII, Madrid, Ministerio de Defensa, 2005: 71-94.

Comoli, Vera, «La fortificazione alla moderna negli stati sabaudi come sistema territoriale», en Angela Marino (coord.), Fortezze d'Europa. Forme, professioni e mestieri dell'architettura difensiva in Europa e nel Mediterraneo spagnolo, Roma, Gangemi, 2003: 59-72. 
D’Amico, Stefano, Le contrade e la città. Sistema produttivo e spazio urbano a Milano fra Cinque e Seicento, Milán, Franco Angeli, 1994.

Dameri, Annalisa, Le citta di carta. Disegni dal Krigsarkivet di Stoccolma, Turín, Politecnico di Torino, 2013.

De Caro, Gaspare, «Beretta, Gaspare», en Dizionario biografico degli Italiani, vol. 9, Roma, Treccani, 1967.

Espino López, Antonio, «Las fortificaciones catalanas a finales del siglo XVII: la obra de Ambrosio Borsano», en Arquitectura e Iconografía artística militar en España y América. Siglos XV-XVIII. III Jornadas militares de historia militar, (Sevilla, 9-12 de marzo de 1993), Sevilla, Cátedra General Castaños, Cuartel General de la Región Militar Sur, 1999: 93-116.

Fior, Michela y Viganò, Marino, «Inventario analitico delle cartelle 'Fortificazioni' (260-270bis), Fondo Belgioioso, Biblioteca Trivulziana», Libri \& Documenti, 1/3 (Milán, 2002): 1-189.

Fiorio, Maria Teresa, Le chiese di Milano, Milán, Electa, 2006.

Franchini, Caterina, «L'ingegnere militare verso la specializzazione topografica», en Micaela Viglino y Andrea Bruno jr. (coords.), Gli ingegneri militari attivi nelle terre dei Savoia e nel Piemonte orientale (XVI-XVIII secolo), Florencia, Edifir, 2007: 121-134.

Galera i Monegal, Montserrat, «Cataluña, 1687», en Carmen Líter, María Luisa Martín-Merás y Francisca Sanchís (eds.), Tesoros de la Cartografía Nacional, Madrid, Caja Duero/ Biblioteca Nacional, 2001: 133-135.

Gatti Perer, Maria Luisa, «Per l'avanzamento degli studi sulla difesa della Lombardia spagnola. Il contributo della Raccolta Ferrari», en Graziella Colmuto Zanella y Luciano Roncai (coords.), La difesa della Lombardia spagnola. Atti del convegno di studi La difesa della Lombardia spagnola-Politecnico di Milano, 2-3 aprile 1998, Cremona, Ronca Editore, 2004: 23-36.

Gentile, Guido, «Dalla 'Carta generale de' Stati di S.A.R.', 1680, alla Carta corografica degli Stati di S.M. il Re di Sardegna, 1772», en I rami incisi dell'Archivio di Corte. Sovrani, battaglie, architetture, topografia. Catalogo della mostra Torino, Palazzo Madama, novembre 1981-gennaio 1982, Turín, Archivio di Stato di Torino, 1981: 112-129.

Giannini, Massimo C., «Pratica delle armi e istruzione militare. Cristóbal Lechuga ufficiale e scrittore nella Milano di inizio Seicento», en Mario Rizzo y Giuseppe Mazzocchi (eds.), La Espada y la Pluma. Il mondo militare nella Lombardia spagnola cinquecentesca. Atti del convegno internazionale di Pavia, 16-18 ottobre 1997, Viareggio, Mauro Baroni editore, 2000: 483-515.

Godoy, Josè-A. y Leydi, Silvio, Parate trionfali. Il manierismo nell'arte dell'armatura italiana. Catalogo della mostra «Armature italiane sec. 16. Ginevra, 2003, Milán, 5 Continents, 2003.

Kamen, Henry, Imperio. La forja de España como potencia mundial, Madrid, Aguilar, 2003.

Leydi, Silvio, Le cavalcate dell'ingegnero. L'opera di Gian Maria Olgiati, ingegnere militare di Carlo V, Bologna, Panini, 1989. 
Llobet i Portella, Josep, Documents notarials de la Segarra i l'Urgell relacionats amb la Guerra de Successió (1705-1714), Cervera, Grup de Recerques de les Terres de Ponent, 2014: 22, 67-68 y 122.

Lupi, Giovanni Battista, «La peste del 1630 a Busto Arsizio», en Franco Bertolli y Umberto Colombo (eds.), La peste del 1630 a Busto Arsizio. Riedizione commentata della "Storia" di Giovanni Battista Lupi (Biblioteca reale di Copenaghen), Busto Arsizio, Bramante editrice, 1990.

Maffi, Davide, Il baluardo della corona. Guerra, esercito, finanze e società nella Lombardia seicentesca (1630-1660), Florencia, Felice Le Monnier, 2007.

Maffi, Davide, «Las milicias del Estado de Milán: un intento de control social», en José Javier Ruiz Ibáñez (coord.), Las milicias del Rey de España. Sociedad, política e identidad en las Monarquías Ibéricas, Madrid, Fondo de Cultura Económica y Red Columnaria, 2009: 244-267.

Maffi, Davide, En defensa del Imperio. Los ejércitos de Felipe IV y la guerra por la hegemonía europea (1635-1659), Madrid, Editorial Actas, 2014.

Martí Escayol, Maria Antònia y Espino López, Antoni, Catalunya abans de la Guerra de Successió. Ambrosi Borsano i la creació d'una nova frontera militar, 1659-1700, Catarroja/Barcelona, Editorial Afers, 2013.

Monsaingeon, Guillaume, «Vauban a-t-il raté la Révolution cartographique?», en Thierry Martin y Michèle Virol (eds.), Vauban, architecte de la modernité?, París, Presses universitaires de Franche-Comté, 2008: 233-261.

Morello, Carlo, Avvertimenti sopra le fortezze di S.R.A. del capitano Carlo Morello primo ingegniere et logotenente generale di sua arteglieria. 1656, (Manoscritti Militari 178), Turín, Biblioteca reale/Consiglio regionale del Piemonte/B.L.U., 2001.

Nadal, Francesc, «El Mapa de Catalunya d'Ambrosio Borsano (1687)», en Jesús Burgueño (ed.), El mapa com a llenguatge geogràfic. Recull de textos històrics (ss. XVII-XX), Barcelona, Societat Catalana de Geografia, 2008: xxiii-xxix.

Nadal, Francesc, «Els plànols i la vista de Barcelona d'Ambrosio Borsano, 16731693», Barcelona Quaderns d'Història, 22 (Barcelona, 2015): 19-32.

Parker, Geoffrey, El Ejército de Flandes y el Camino Español, 1567-1659, Madrid, Alianza Editorial, 1985.

Parker, Geoffrey, «El desarrollo de la crisis», en Geoffrey Parker (coord.), La crisis de la Monarquía de Felipe IV, Barcelona, Crítica y Universidad de Valladolid, 2006: 17-170.

Parrott, David, «France's War against the Habsburgs, 1624-1659: the Politics of Military Failure», en Enrique García Hernán y Davide Maffi (eds.), Guerra y Sociedad en la Monarquía Hispánica: política, estrategia y cultura en la Europa moderna (1500-1700), vol. 1, Madrid, Ediciones del Laberinto/Fundación Mapfre/CSIC, 2006: 31-48.

Pollak, Martha D., Military Architecture Cartography and the representation of the early modern European city: a checklist of treatises of fortification in the Newberry Library, Chicago, The Newberry Library, 1991. 
Possi, Lorenzo, «Piante d'Estremadura, e di Catalogna», en Carlos Sánchez Rubio, Rocío Sánchez Rubio e Isabel Testón Nuñez (eds.), El Atlas de Lorenzo Possi. 1687. Piante d'Estremadura, e di Catalogna, Badajoz, 4 Gatos, 2014.

Repishti, Francesco, «Architetti e ingegneri comunali, ducali e camerali nella Milano sforzesca e spagnola», en Paolo Bossi, Santino Langé y Francesco Repishti (eds.), Ingegneri ducali e camerali nel Ducato e nello Stato di Milano (1450-1706). Dizionario biobibliografico, Florencia, Edifir, 2007: 23-31.

Rizzo, Mario, «Haver sempre l'occhio all'abondanza dei viveri. Il governo dell'economia pavese durante 1'assedio del 1655», en Antonio Miguel Bernal, Luigi De Rosa y Francesco D'Esposito (eds.), El Gobierno de la economía en el imperio español: información estadística, política económica y fiscalidad, Sevilla/Nápoles, Fundación El Monte/Istituto italiano per gli studici filosofici, 2000: 471-507.

Rizzo, Mario, «Ottima gente da guerra. Cremonesi al servizio della strategia imperiale», en Giorgio Politi (ed.), Storia di Cremona. L'età degli Asburgo di Spagna (1535-1707), Cremona, Banca Cremonese, 2006: 126-145.

Rizzo, Mario, «Armi di Lombardia. Lo Stato di Milano e le forniture belliche agli Asburgo di Spagna fra Cinque e Seicento», en Antonino Giuffrida, Fabrizio D'Avenia y Daniele Palermo (eds.), Studi storici dedicati a Orazio Cancila, Palermo, Associazione Mediterranea, 2011: 317-344.

Rizzo, Mario, «Influencia social, conveniencia económica, estabilidad política y eficiencia estratégica. Notables lombardos al servicio de los Habsburgo en la segunda mitad del siglo XVI», en Juan Francisco Pardo Molero y Manuel Lomas Cortés (coords.), Oficiales reales. Los ministros de la Monarquía Católica (siglos XVI-XVII), València, Universitat de València y Red Columnaria, 2012: 163-202.

Rizzo, Mario, «Demografia, sussistenza e governo dell'emergenza a Pavia durante l'assedio del 1655», en Alessandro Buono y Gianclaudio Civale (eds.), Battaglie. L'evento, l'individuo, la memoria, Palermo, Associazione Mediterranea, 2014a: 59-97.

Rizzo, Mario, «Il mestiere delle armi nell'Italia moderna fra esercizio del potere, creazione del consenso, formazione e impiego del capitale umano (secc. XVIXVIII)», en Paola Bianchi y Nicola Labanca (eds.), L'Italia e il 'militare'. Guerre, nazione, rappresentazioni dal Rinascimento alla Repubblica, Roma, Edizioni di Storia e Letteratura, 2014b: 75-101.

Rizzo, Mario y Mazzocchi, Giuseppe (eds.), La Espada y la Pluma. Il mondo militare nella Lombardia spagnola cinquecentesca. Atti del convegno internazionale di Pavia, 16-18 ottobre 1997, Viareggio, Mauro Baroni editore, 2000.

Rodríguez Hernández, Antonio José, «Al servicio del Rey. Reclutamiento y transporte de soldados italianos a España para luchar en la Guerra contra Portugal (16401668)», en Davide Maffi (ed.), Tra Marte e Astrea. Giustizia e giurisdizione militare nell'Europa della prima età moderna (secc. XVI-XVIII), Annali di Storia Militare Europea, vol. 4, Milán, FrancoAngeli, 2012: 229-275.

Roncai, Luciano, «Gaspare Beretta», en Paolo Bossi, Santino Langé y Francesco Repishti (eds.), Ingegneri ducali e camerali nel Ducato e nello Stato di Milano (1450-1706). Dizionario biobibliografico, Florencia, Edifir, 2007: 44-46. 
Sánchez Rubio, Carlos, Sánchez Rubio, Rocío y Testón Núñez, Isabel, El Atlas Medici de Lorenzo Possi 1687. Piante d'Estremadura, e di Catalogna, Badajoz, 4 Gatos, 2014.

Sánchez Rubio, Rocío, Testón Núñez, Isabel y Sánchez Rubio, Carlos, «Plantas de diferentes plazas de España, Italia, Flandes y las Indias», en Rocío Sánchez Rubio, Carlos Sánchez Rubio e Isabel Testón Núñez (eds.), Imágenes de un imperio perdido. El Atlas del Marqués de Heliche, Badajoz, Junta de Extremadura, 2004: 19-38.

Scotti, Aurora, «Lo Stato di Milano», en Aurora Scotti (coord.), Storia dell'architettura italiana. Il Seicento, vol. II, Milán, Mondadori Electa, 2003: 424-469.

Signorotto, Gianvittorio, Milano spagnola. Guerra, istituzioni, uomini di governo (1635-1660), Florencia, Sansoni, 1996.

Spini, Giorgio, Storia dell'età moderna. II. 1598-1661, Turín, Einaudi, 1965.

Testón Núñez, Isabel, Sánchez Rubio, Carlos y Sánchez Rubio, Rocío, Planos, guerra y frontera. La Raya Luso-Extremeña en el Archivo Militar de Estocolmo, Badajoz, Gabinete de Iniciativas Transfronterizas/Junta de Extremadura, 2003.

Testón Núñez, Isabel, Sánchez Rubio, Rocío y Sánchez Rubio, Carlos, La memoria ausente. Cartografía de España y Portugal en el Archivo Militar de Estocolmo. Siglos XVII y XVIII, Badajoz, 4 Gatos, 2006, 1 CD.

Valladares, Rafael, La rebelión de Portugal (1640-1680). Guerra, conflicto y poderes en la Monarquía Hispánica, Valladolid, Junta de Castilla y León, 1998.

Viganò, Marino, «Le portefeuille de Gaspare Beretta (1620-1703) à la Bibliothèque Trivulziana de Milan: plans et mémoires pour servir l'Espagne», en Archives départamenteles $d u$ Cher, Portefeuilles de plans. Projets et dessins d'ingénieurs militaires en Europe du XVIè au XIXè siècle. Actes du colloque international de Saint-Amand-Montrond, 2 et 3 mars 2001, Bourges, Conseil général du Cher, 2001: 147-158.

Viglino, Micaela, «Un erede di esperti nell'arte fortificatoria e nel disegno», en Micaela Viglino y Claudia Bonardi Tomesani (coords.), Città munite, fortezze, castelli nel tardo Seicento. La raccolta di disegni "militari" di Michel Angelo Morello, Roma, Istituto Italiano dei Castelli, 2001: 7-14.

Viglino, Micaela, "Autenticità e copia nei disegni di architettura militare», en Angela Marino (coord.), L'architettura degli ingegneri. Fortificazioni in Italia tra'500e '600, Roma, Gangemi, 2005: 9-26.

Viglino, Micaela, Chiodi, Elisabetta, Franchini, Caterina y Perin, Antonella, Architetti e ingegneri militari in Piemonte tra '500 e '700, Turín, Omega edizioni, 2008.

Warmoes, Isabelle, d'Orgeix, Emilie y Van den Heuvel, Charles (eds.), Atlas militaires manuscrits européens (XVIe-XVIIIe siècles). Forme, contenu, contexte de réalisation et vocations, París, Musée des Plans-Reliefs, 2003.

Recibido: 01/03/2016

Aprobado: 26/10/2016 